This is the peer reviewed version of the following article: A. L. Sahlberg, J. Zhou, M. Aldén, and Z. $\mathrm{S}$. Li, "Investigation of ro-vibrational spectra of small hydrocarbons at elevated temperatures using infrared degenerate four-wave mixing", J. Raman Spectrosc., 47, 1130-1139, (2016), which has been published in final form at [https://doi.org/10.1002/jrs.4862]. This article may be used for non-commercial purposes in accordance with Wiley Terms and Conditions for Use of SelfArchived Versions. 


\title{
Investigation of ro-vibrational spectra of small hydrocarbons at elevated temperatures using infrared degenerate four-wave mixing
}

\author{
Anna-Lena Sahlberg, Jianfeng Zhou, Marcus Aldén and Zhongshan Li
}

\begin{abstract}
The ro-vibrational spectra around $3 \mu \mathrm{m}$ of four small hydrocarbons $\left(\mathrm{C}_{2} \mathrm{H}_{2}, \mathrm{CH}_{4}, \mathrm{C}_{2} \mathrm{H}_{6}, \mathrm{C}_{2} \mathrm{H}_{4}\right)$ at 296, 550 and $820 \mathrm{~K}$ have been investigated using infrared degenerate four-wave mixing (IRDFWM). The spectra were recorded in gas flows of nitrogen with small admixtures of the hydrocarbons. A fused silica glass tube surrounded by an electric heating wire was used to heat the gas flows. The recorded IR-DFWM spectra are compared to simulations using the spectral information available in the HITRAN database, in order to identify spectral lines. The measurements demonstrate good signal to noise ratio and good sensitivity even at elevated temperatures. Several weak hot lines were detected that are not included in the current database. This paper demonstrates the potential of IR-DFWM for purposes of investigating spectral lines at elevated temperatures, which is often a challenging task with conventional absorption spectroscopy techniques. The possibility of applying IR-DFWM for combustion diagnostics of small hydrocarbons is discussed from the detection limits of the measurements and the potential water line interference. Due to the non-linear nature of the DFWM technique, it provides much higher contrast for strong lines of small molecules over backgrounds of high density weak lines, which commonly exist in hot gas flows of thermochemical reactions.
\end{abstract}

Keywords: degenerate four-wave mixing, mid-infrared, hydrocarbons

\section{Introduction}

Degenerate four-wave mixing (DFWM) is a nonlinear laser technique that has been widely applied to detection of molecular species at trace level concentrations in harsh environments like combustion. DFWM is a coherent, zero-background technique, where the signal is generated as a coherent laser beam that can be readily separated from incoherent background. A theoretical model has been presented by Abrams and Lind ${ }^{[1,2]}$ in 1978. DFWM is a sensitive, non-intrusive measurement technique with high spatial and temporal resolution. DFWM has been widely applied in the visible/UV spectral regions for detection of atoms and molecules with accessible electronic transitions (see e.g. ${ }^{[3-6]}$ ).

Mid-infrared degenerate four-wave mixing (IR-DFWM) has been less frequently applied, in part due to the relatively less availability of high power lasers and sensitive detectors in this spectral region. Many important species in combustion, e.g. $\mathrm{CH}_{4}, \mathrm{C}_{2} \mathrm{H}_{4}, \mathrm{C}_{2} \mathrm{H}_{6}, \mathrm{HCN}$ and $\mathrm{HCl}$, lack accessible transitions in the visible/ultraviolet region. IR-DFWM offers the potential to study these molecules in the mid-infrared spectral region utilizing molecular ro-vibrational transitions. IRDFWM has been demonstrated in detection of, e.g. $\mathrm{CH}_{4},{ }^{[7]} \mathrm{HF}^{[8]}$ and $\mathrm{C}_{2} \mathrm{H}_{2},{ }^{[9]}$ and has been found to be a sensitive laser technique. In recent years, the detectors in the mid-infrared region have improved, making detection in the mid-IR more feasible. Sun et al. developed a set of IR-BOXCAR plates for stable and easy alignment of the forward phase-matching geometry in the mid-IR. ${ }^{[10]} \mathrm{A}$ 
similar setup has been used for detection of $\mathrm{CH}_{3} \mathrm{Cl}$ in hot gas flows. ${ }^{[11]}$ Dam et al. recently introduced a low noise upconversion detector for sensitive and low noise detection of mid-infrared light ${ }^{[12]}$ and the detector was reported to greatly enhance the sensitivity of the IR-DFWM technique. ${ }^{[13]}$

The detection of small hydrocarbons and other molecular species in the mid-infrared is important for combustion diagnostics. Detection of $\mathrm{C}_{2} \mathrm{H}_{2}$ has been demonstrated using coherent anti-Stokes Raman scattering (CARS). ${ }^{[14]}$ Like DFWM, CARS is a four-wave mixing technique, but is limited to major species detection due to the inherently weak Raman process. Sensitive detection of $\mathrm{C}_{2} \mathrm{H}_{2}$ has been demonstrated using electronic resonance enhanced CARS (ERE-CARS) with the probe beam resonant with the A-X electronic transition around $236 \mathrm{~nm}$ to increase the signal. ${ }^{[15]}$ However, ERE-CARS is limited to species which have accessible electronic resonances. For species which lack these transitions, but have infrared active absorption bands, IR-DFWM could be a very powerful technique for species detection in flames.

In flames, due to the high temperatures, the structure of the spectral lines is different from that of room-temperature spectra. In addition to this, there is often severe interference from hot water vapor, which has a large number of absorption lines in the mid-infrared. Thus, it is important to have knowledge of line positions and the relative line strength of these molecules at elevated temperatures, to facilitate identification of species from recorded spectra. Unfortunately, the information on line position and strength for small hydrocarbons, like $\mathrm{CH}_{4}, \mathrm{C}_{2} \mathrm{H}_{2}, \mathrm{C}_{2} \mathrm{H}_{4}$ and $\mathrm{C}_{2} \mathrm{H}_{6}$ in the HITRAN database ${ }^{[16]}$ is not always complete at elevated temperatures.

Recently, Alrefae et a ${ }^{[17]}$ reported a measurement of mid-infrared absorption cross section of $\mathrm{CH}_{4}$, $\mathrm{C}_{2} \mathrm{H}_{2}, \mathrm{C}_{2} \mathrm{H}_{4}$ and $\mathrm{CH}_{3} \mathrm{OH}$ at temperatures up to $1120 \mathrm{~K}$ using a Fourier-Transform Infrared (FTIR) spectrometer. FTIR is a very useful device for measuring infrared absorption cross-sections over a wide range of wavelengths. The main hardship in using a line-of-sight technique like FTIR at higher temperatures is the difficulty of creating a sample with homogeneous temperature along the whole measurement path. Temperature variations along the measurement path can introduce distortions in the spectral features. IR-DFWM, as a technique with high spatial resolution, is ideal for high temperature measurements, since the gas temperature only needs to be homogeneous in a small detection volume. So the IR-DFWM technique can be useful as a complement to FTIR for detection of line positions and relative intensities of hot lines crucial for spectroscopic data simulations. Also, the nonlinear nature of the DFWM technique provides much higher contrast for strong lines of small molecules over backgrounds of high density weak lines, which commonly exist in combustion environments.

In this work, sensitive detection of $\mathrm{C}_{2} \mathrm{H}_{2}, \mathrm{CH}_{4}, \mathrm{C}_{2} \mathrm{H}_{4}$ and $\mathrm{C}_{2} \mathrm{H}_{6}$ using IR-DFWM at trace level concentrations at 296, 550 and $820 \mathrm{~K}$ is demonstrated by probing the ro-vibrational transitions around $3 \mu \mathrm{m}$. The gas flows of hydrocarbon and nitrogen were flushed through an open-ended fused silica glass tube surrounded by electric heating wire. The detection limit for each species was determined at 296, 550 and $820 \mathrm{~K}$ for each molecular species and the spectra are compared to simulations using the HITRAN database. For combustion applications, the interference from water vapor is discussed from measurements of the $\mathrm{H}_{2} \mathrm{O}$ spectrum at $820 \mathrm{~K}$ and from simulations using the HITEMP database. ${ }^{[18]}$ This work shows the potential of IR-DFWM both for spectroscopic 
studies of molecular species at higher temperatures, and for applications to detect hydrocarbon fuels and intermediate species in combustion situations.

\section{Experimental setup}

A schematic of the IR-DFWM setup used in the experiments is shown in Figure 1. The mid-infrared laser system has been described previously ${ }^{[19]}$ and only a brief description is given here for completeness. The second harmonic of an injection seeded Nd:YAG laser (Spectra Physics, PRO 290-10) was used to pump a dye laser (Sirah, PRSC-D-18), generating tunable laser light around $790 \mathrm{~nm}$. The dye laser light was then frequency mixed in a $\mathrm{LiNBO}_{3}$ crystal with part of the residual $1064 \mathrm{~nm}$ output from the Nd:YAG laser. This light was further amplified in another $\mathrm{LiNBO}_{3}$ crystal, to provide mid-infrared laser light tunable from 2900 to around $3400 \mathrm{~cm}^{-1}$ with pulse energies around 4-5 mJ and a pulse duration of 3-4 ns. A telescope was used to shrink the beam size down to approximately $2 \mathrm{~mm}$. The reflection from a $\mathrm{CaF}_{2}$ window was sent to a power meter to monitor the laser energy during the scan.

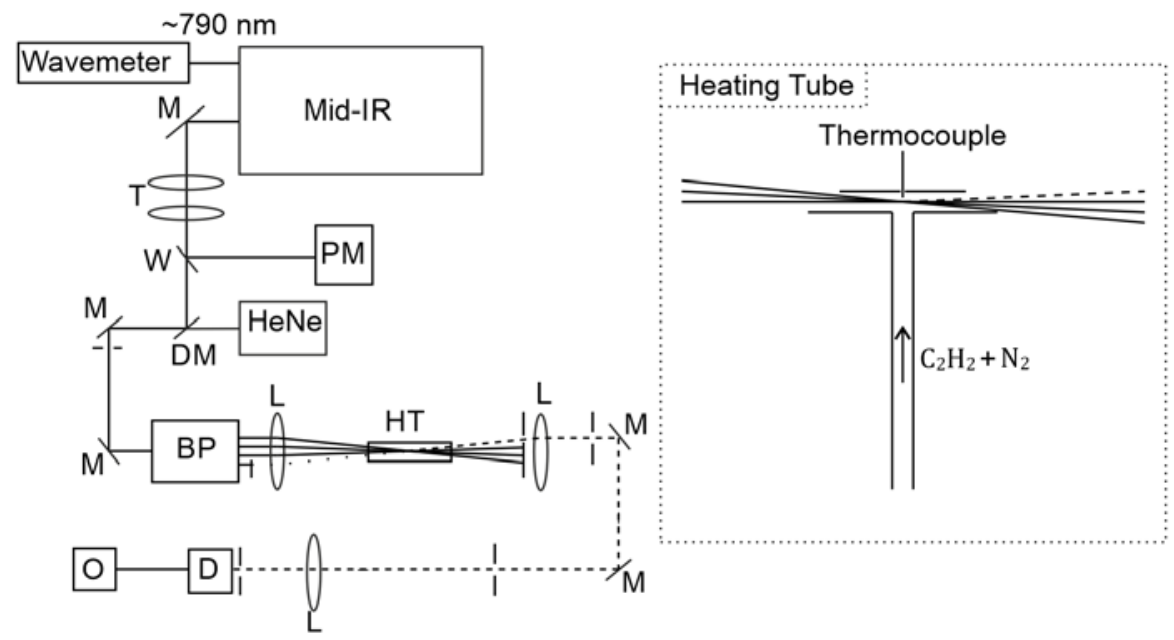

Figure 1. Schematic of the experimental setup. M: gold mirror, T: telescope, $W$ : CaF 2 window, PM: power meter, DM: dichroic mirror, BP: BOXCAR plates, L: CaF 2 lens, HT: heating tube, D: InSb detector, O: oscilloscope.

The IR laser beam was overlapped with a He-Ne laser beam to facilitate the optical alignment. The laser beam was then split into four beams using the specially designed IR-BOXCAR plates. A detailed description of the BOXCAR plates can be found in Ref. ${ }^{[10]}$ Three of the beams were crossed in the middle of the heating gas tube using an $f=500 \mathrm{~mm} \mathrm{CaF}_{2}$ lens. The fourth beam was used to trace the signal beam to the detector, since this beam follows the signal beam path. The signal beam was collimated by another $f=500 \mathrm{~mm} \mathrm{CaF} 2$ lens, and then detected by a liquid nitrogen cooled InSb detector (Judson technologies, J10D-M204-R04M-60). Part of the residual dye laser beam after the frequency mixing was directed to a wavemeter (HighFinesse, WS/6 High Precision - UV), to monitor the laser wavelength during the scan. The wavemeter has an accuracy of 600 $\mathrm{MHz}$. For these experiments, a wavelength accuracy of $\pm 0.1 \mathrm{~cm}^{-1}$ was estimated, due to the uncertainty of the process for synching the laser scan with the wavemeter. 
The sample of hydrocarbon gas $\left(\mathrm{C}_{2} \mathrm{H}_{2}, \mathrm{CH}_{4}, \mathrm{C}_{2} \mathrm{H}_{6}\right.$ or $\left.\mathrm{C}_{2} \mathrm{H}_{4}\right)$ mixed with $\mathrm{N}_{2}$ was prepared as a continuous flow through an open $\mathrm{T}$-shaped gas tube surrounded by electric heating wire and insulation, see Figure 1. The gas flows were controlled by Bronkhorst mass flow controllers, and the concentration of the hydrocarbon species was controlled by adjusting the relative flows of the gases through the gas tube. The total flow of the gases through the tube was around $4.5 \mathrm{l} / \mathrm{min}$, giving a flow speed at room temperature of $25 \mathrm{~cm} / \mathrm{s}$. The utilization of fused silica glass as the inside wall of the electronic heater is to avoid catalyst effects. The pyrolysis and thermal decomposition of the hydrocarbons in the gas flow was assumed to be negligible for the temperatures and flow speeds used in these experiments. ${ }^{[17,20-22]}$

The interaction volume of the IR-DFWM beams was estimated to be $\sim 0.6 \times 0.6 \times 15 \mathrm{~mm}^{3}$. A thermocouple was inserted through the top of the gas tube to measure the temperature of the gas $\sim 1 \mathrm{~mm}$ beside the measurement point of the laser beams. The temperature in the interaction region was assumed to be uniform and as what the thermocouple measured.

\section{Spectroscopy of the selected hydrocarbons}

Most hydrocarbons species exhibit an infrared ro-vibrational spectrum around $3 \mu \mathrm{m}$ from the $\mathrm{C}-\mathrm{H}$ stretching vibration. The spectrum varies for different hydrocarbons depending on molecular weight, structure and symmetry. The HITRAN database ${ }^{[16]}$ contains line-list information about all four species studied here. The two strongest bands for $\mathrm{C}_{2} \mathrm{H}_{2}$ in this spectral region are the $v_{3}$ band and the $v_{2}+\left(v_{4}+v_{5}\right)^{0}$ band, centered around $3300 \mathrm{~cm}^{-1}$, both bands exhibiting a $P R$-structure. For $\mathrm{CH}_{4}$, the strongest transitions are from the asymmetric stretching vibration mode $v_{3}$ around 3000 $\mathrm{cm}^{-1}$, with each rotational line split into a tetrahedral symmetry fine structure. The strongest $\mathrm{C}_{2} \mathrm{H}_{4}$ transitions in this spectral region originate from the $v_{9}$ band centered around $3105 \mathrm{~cm}^{-1}$ and the $v_{11}$ band centered around $2988 \mathrm{~cm}^{-1}$. The ro-vibrational spectrum of the $v_{9}$ and $v_{11}$ bands is complicated and contains many $P, R$ and $Q$-branch lines.

For $\mathrm{C}_{2} \mathrm{H}_{6}$, the strongest lines in this spectral region originate from the ${ }^{R} Q_{K}$ lines from the $v_{7}$ band, but the spectrum also contains weaker $P$-and- $R$ branch lines from the $v_{7}$ band and lines from the $v_{1}$ and $v_{10}$ bands. ${ }^{[17]}$ The HITRAN line list of vibrational transitions for $\mathrm{C}_{2} \mathrm{H}_{6}$ is not complete in this spectral region, containing only information for the strongest ${ }^{R} Q_{K}$-branch lines of the $v_{7}$ band. Highresolution absorption cross sections of $\mathrm{C}_{2} \mathrm{H}_{6}$ in this spectral region have been measured by Harrison et al. ${ }^{[23]}$ using an FTIR spectrometer, showing the system of weaker lines around the strong ${ }^{R} Q_{K^{-}}$ branch lines from the $v_{7}$ band, and the cross sections are available in the HITRAN database. ${ }^{[16]}$ This data is highly useful for performing spectroscopic measurements of $\mathrm{C}_{2} \mathrm{H}_{6}$ in this spectral region. Comparisons to these measurements can be used to validate other spectroscopic data, even in the cases where the used measurement techniques are different from FTIR.

\section{Measurement and results}

\section{DFWM theory}

A theoretical model for simulating the DFWM signal was presented by Abrams and Lind ${ }^{[1,2]}$ in 1978. Their approach treated the case of a monochromatic laser field interacting with an optically thin medium of stationary two-level atoms. The laser beams were arranged in the phase conjugate 
geometry and the probe laser field was assumed to be weak, while the pump beam fields intensity was arbitrary. Solving the wave equations gave the line-integrated DFWM signal by the following equations for non-saturating and saturating pump beams, respectively ${ }^{[24]}$

$$
\begin{array}{cc}
I_{D F W M} \propto \frac{\mu^{8} N^{2} k^{2} T_{1}^{2} T_{2}^{3}}{\left(1+4 I_{\text {pump }} / I_{\text {sat }}\right)} I_{\text {pump }}^{2} I_{\text {probe }} & I_{\text {pump }} \ll I_{\text {sat }} \\
I_{D F W M} \propto \mu^{3} N^{2} k^{2} T_{1}^{-1 / 2} T_{2}^{1 / 2} I_{\text {pump }}^{-1 / 2} I_{\text {probe }} & I_{\text {pump }} \geq I_{\text {sat }}
\end{array}
$$

Where $\mu$ is the transition dipole moment of the transition, $N$ is the number density, $k$ is the Boltzmann constant, $T_{1}$ is the longitudinal relaxation time of the transition, $T_{2}$ is the transverse relaxation time, $I_{\text {pump }}$ is the pump laser intensity, $I_{\text {probe }}$ is the probe intensity and $I_{\text {sat }}$ is the saturation intensity of the transition.

In practice, it is preferable to perform degenerate four-wave mixing with saturating intensities in both the pump and the probe beams. This case is more complicated than the case treated by Abrams and Lind. Generally, finding an analytical expression for the DFWM signal that satisfies all experimental conditions is very difficult. Direct-numerical integration (DNS) is computationally expensive but can be successfully used for DFWM mixing simulations under most conditions (see e.g. ${ }^{[25-28]}$ ). An analytical model for arbitrary pump and probe intensities, more complicated than the Abrams and Lind model, has been developed and applied successfully in the case of optically thin media and two-level atoms ${ }^{[29]}$ and has been shown to successfully simulate saturation effects in DFWM signals. ${ }^{[30]}$

The IR-DFWM signal intensity dependence on the transition dipole moment $\mu$ of a transition for different degree of saturation has been investigated experimentally by Farrow and Rakestraw. ${ }^{[3]}$ It was found that the signal dependence ranged from $\mu^{4}$ for saturating pump beams to $\mu^{11}$ for unsaturating beams. This is slightly different from the theoretically predicted dependence of $\mu^{3}$ and $\mu^{8}$ for saturating and unsaturating beams, respectively. It was believed that the exponent would approach 3 in the limit of strong saturation.

Simulation of the DFWM signal is even more complex when dealing with closely spaced transitions. Signals from different transitions can interact coherently, and thus the resulting signal will be different from the sum of the signals. Studies show that the signals of closely spaced transitions are strongly dependent on the degree of saturation of the beams. ${ }^{[27,30]}$ It has also been shown in a previous study ${ }^{[11]}$ that the IR-DFWM signals for many closely spaced transitions present for example in $Q$-branch lines are much enhanced compared to the IR-DFWM signal from isolated transitions. The ro-vibrational spectra of hydrocarbons in the mid-infrared usually contain a large number of lines, increasing in complexity with larger molecules. Extensive theoretical and numerical simulations would be needed to fully simulate the IR-DFWM spectra of these molecules, which is outside the scope of this article. In this article, the IR-DFWM spectra were instead 
simulated using data from the HITRAN database and an empirical formula, ${ }^{[1,19]}$ where the IRDFWM signal is simulated by

$$
I_{D F W M} \propto N^{2} \sigma(v)^{2}
$$

$\sigma(v)$ is the absorption cross section for wavenumber $v$ which is calculated as

$$
\sigma(v)=\sum_{i} S_{i} g(v)
$$

Where $S_{i} \propto \mu^{2}$ is the line intensity for transition $i$ given in the HITRAN database and $g(v)$ is the line shape of the transitions. In the IR-DFWM simulation in this paper, an $S^{2} \propto \mu^{4}$ dependence of the signal was assumed in accord with Farrow and Rakestraw. ${ }^{[3]}$ This dipole moment dependence has previously been shown as a good representation of the IR-DFWM signal for similar laser intensities. ${ }^{[11]}$ An empirical Voigt profile was used in the simulations with parameters chosen to match the observed experimental line shapes. This has been shown previously to be a good estimation of the IR-DFWM signal line shape. ${ }^{[10]}$ The effect of collisional quenching and relaxation times for different transitions in the spectra has not been taken into account in the simulations. The intensities of the simulated signals have been adjusted for the best overall match with the experimental intensity.

Discrepancies between the simulations and our observed experimental spectra can be explained by several reasons. Firstly, the multi-mode nature of the laser pulses has been known to give an unstable shot-to-shot signal intensity, which can account for uneven line shapes and deviations in the peak signal intensity. This problem could be solved by application of a single-mode laser. ${ }^{\text {[31] }}$ Secondly, the simple empirical model used in our simulations might not be completely accurate in the simulation of the complex ro-vibrational spectra. Finally, for some of the molecules studied the data available in the HITRAN database is not complete, and the lack of information from some transitions makes it impossible to do a perfect simulation of the spectra.

$\mathrm{C}_{2} \mathrm{H}_{2}$

The IR-DFWM excitation scan recorded at $820 \mathrm{~K}$ in a gas flow containing $1100 \mathrm{ppm}_{2} \mathrm{H}_{2}$ is shown in Figure 2 (blue) compared with the simulated IR-DFWM signal (red). Line identification of $P$ and- $R$ branch lines belonging to the $v_{3}$ and $v_{2}+\left(v_{4}+v_{5}\right)^{0}$ bands are shown in the figure. The simulation and measurement agree reasonably well. Some detail discrepancies in line intensity between the measurement and the simulation are probably due to the multi-mode property of the excitation laser, which causes unstable signal intensity due to shot-to-shot variations in the mode structure of the laser pulse. The measured and simulated IR-DFWM spectra at 296 and $550 \mathrm{~K}$ are shown in Supplementary information, Figure S1. Text files containing the raw data for the measured spectra are also included in Supplementary information. 


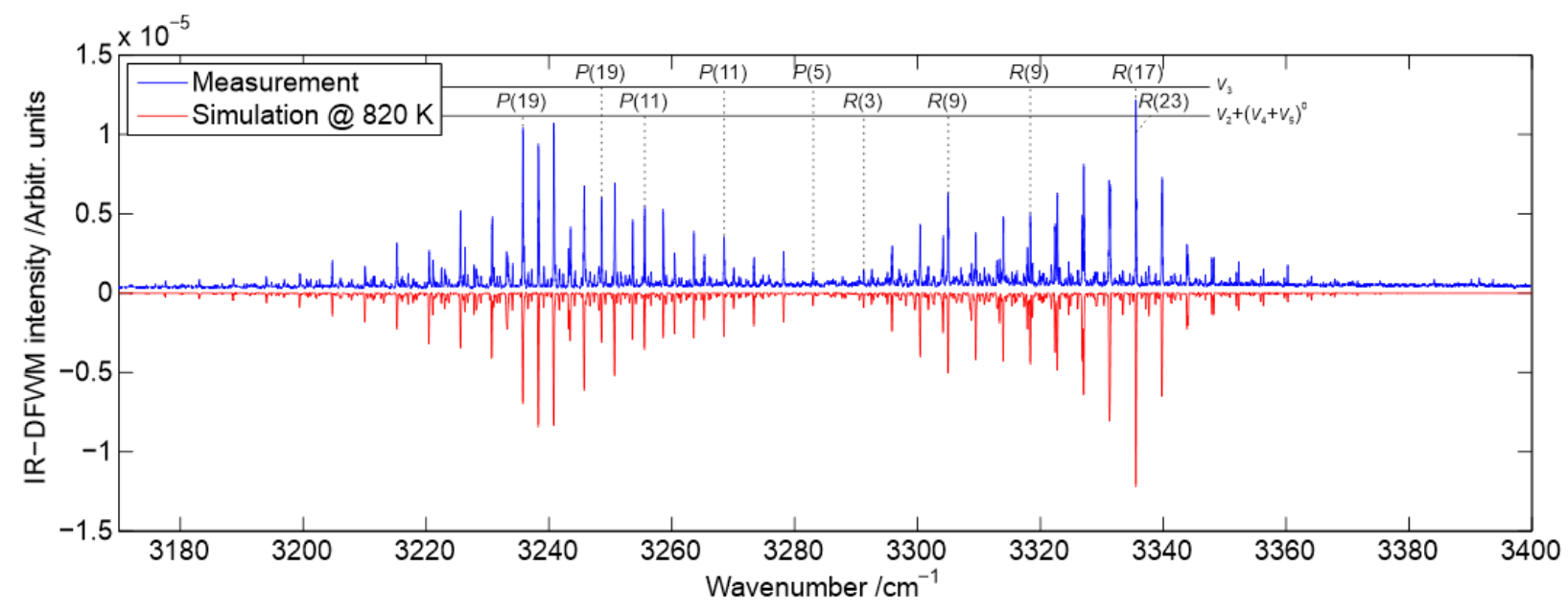

Figure 2. Infrared degenerate four-wave mixing (IR-DFWM) spectrum of $1110 \mathrm{ppm} \mathrm{C}_{2} \mathrm{H}_{2}$ diluted in $N_{2}$ at $820 \mathrm{~K}$. The intensity of the simulated spectrum was normalized to the best fit to the measurements.

Figure 3 shows the $\mathrm{C}_{2} \mathrm{H}_{2}$ IR-DFWM spectrum at $820 \mathrm{~K}$ in the interval $3320-3335 \mathrm{~cm}^{-1}$. In addition to the strong lines from the fundamental bands, there are several transitions from hot bands that start to gain intensity with the higher temperature. Selected lines from the $v_{3}+v_{4}{ }^{1}-v_{4}{ }^{1}, v_{3}+v_{5}{ }^{1}-v_{5}{ }^{1}$ and $v_{2}+\left(2 v_{4}+v_{5}\right)^{1}-v_{4}{ }^{1}$ bands are identified in the figure. Comparing the measurement and the simulation shows that the information of $\mathrm{C}_{2} \mathrm{H}_{2}$ hot bands in HITRAN in this spectral region is quite complete at this temperature. As a linear molecule, the $\mathrm{C}_{2} \mathrm{H}_{2}$ spectrum is relatively uncomplicated. It is clear that the empirical model for DFWM simulation used here works very well for simulations of the $\mathrm{C}_{2} \mathrm{H}_{2}$ spectrum.

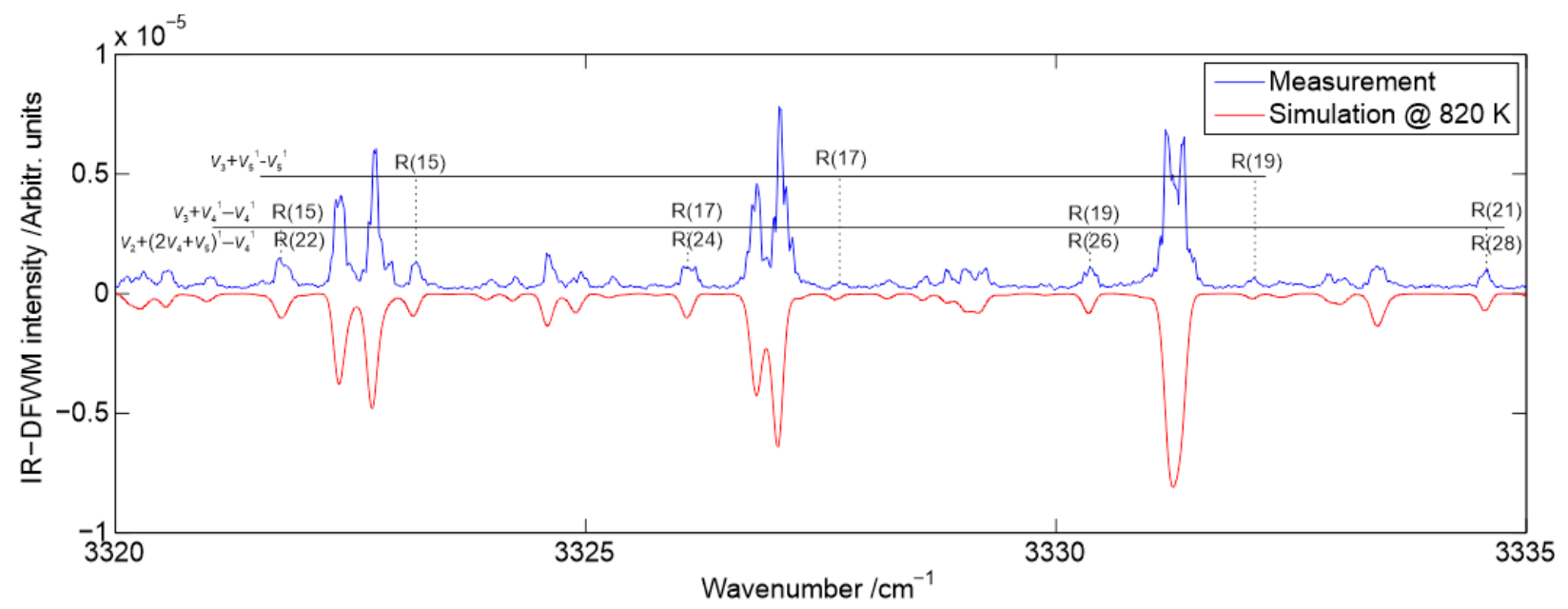

Figure 3. Infrared degenerate four-wave mixing (IR-DFWM) spectrum of $1110 \mathrm{ppm} \mathrm{C}_{2} \mathrm{H}_{2}$ diluted in $N_{2}$ at $820 \mathrm{~K}$ in the interval 3320-3335 $\mathrm{cm}^{-1}$. Selected lines from the $v_{3}+v_{4}{ }^{1}-v_{4}{ }^{1}, v_{3}+v_{5}{ }^{1}-v_{5}{ }^{1}$ and $v_{2}+\left(2 v_{4}+v_{5}\right)^{1}-v_{4}{ }^{1}$ hot bands are identified in the figure. The intensity of the simulated spectrum was normalized to the best fit to the measurements. 


\section{$\mathrm{CH}_{4}$}

The IR-DFWM excitation scan recorded at $820 \mathrm{~K}$ in a gas flow containing $700 \mathrm{ppm} \mathrm{CH}_{4}$ is shown in Figure 4 (blue) compared with the simulated IR-DFWM signal (red). Line identification of selected $R$ branch lines belonging to the $v_{3}$ band is included in the measurement. The measured and simulated IR-DFWM spectra at 269 and $550 \mathrm{~K}$ are shown in Supplementary information Figure S2. Text files containing the raw data for the measured spectra are also included in Supplementary information. Reasonably good agreement between the line intensity of the measurement and simulation is achieved at all temperatures.

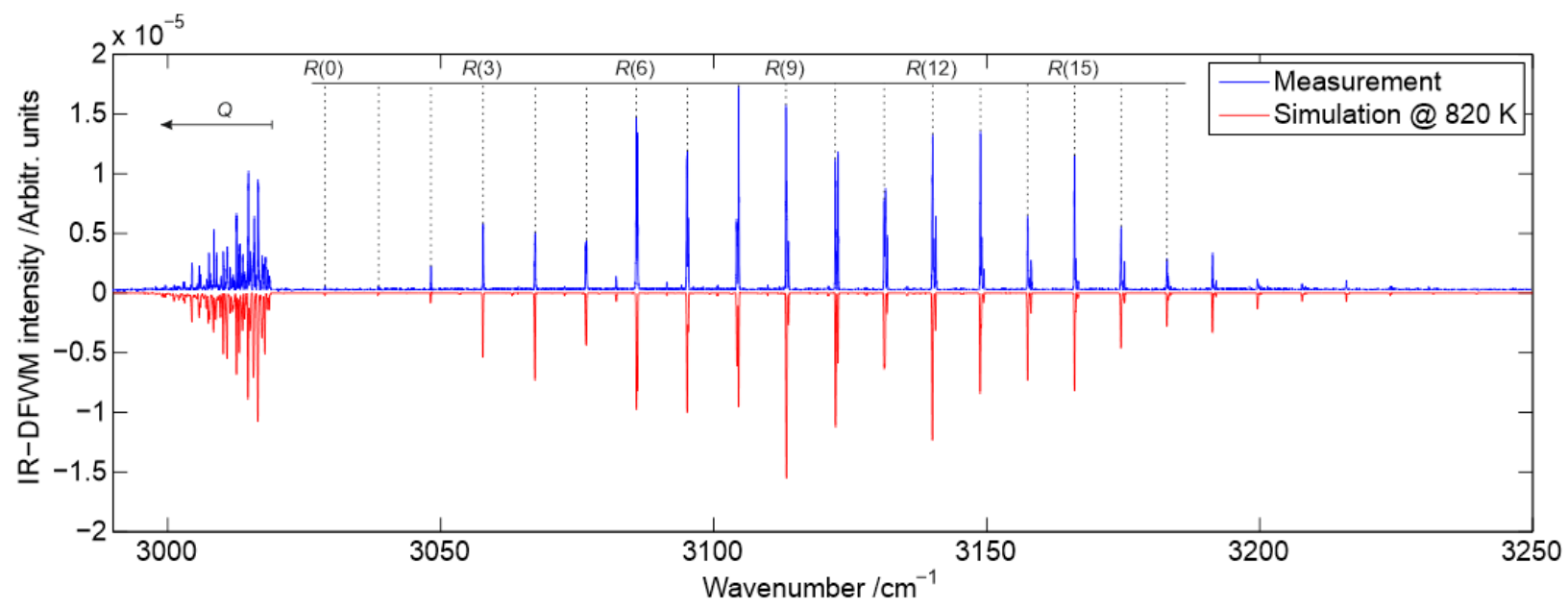

Figure 4. Infrared degenerate four-wave mixing (IR-DFWM) spectrum of $700 \mathrm{ppm} \mathrm{CH}_{4}$ diluted in $\mathrm{N}_{2}$ at $820 \mathrm{~K}$. The intensity of the simulated spectrum was normalized to the best fit to the measurements.

Figure 5 shows the $\mathrm{CH}_{4}$ IR-DFWM spectrum at $820 \mathrm{~K}$ in the interval $3130-3200 \mathrm{~cm}^{-1}$. This spectrum was recorded at a higher $\mathrm{CH}_{4}$ concentration in order to highlight the weaker hot lines. This also means that the stronger $R$-branch lines from the $v_{3}$ band were saturating the detector in the experiment, and thus the relative intensity of these recorded lines is not a correct indication of the actual signal intensities. The y-axis in Figure 5 has been adjusted to better show the weaker hot lines, and thus the peak intensities of the stronger $R$-branch lines are extended outside of the graph axes. Most of the shown hot lines are identified by comparison with the HITRAN database as $R$ branch lines from the $v_{2}+v_{3}-v_{2}$ and the $v_{3}+v_{4}-v_{4}$ hot bands. Above $3160 \mathrm{~cm}^{-1}$, there are several weak emerging hot lines (numbered 1-8 in the figure) that are not accounted for in the HITRAN database. The position and relative intensity suggests these lines are also $R$-branch lines from the $v_{2}+v_{3}-v_{2}$ and the $v_{3}+v_{4}-v_{4}$ hot bands with higher $J$-values. The line marked "a" at $3181.06 \mathrm{~cm}^{-1}$ matches a $\mathrm{H}_{2} \mathrm{O}$ hot line, so it could arise from water vapor diffusing into the heating tube from the ambient air. $\mathrm{CH}_{4}$ can be found as a major species in some combustion situations (for example, as a part in certain fuels), and in these cases, $\mathrm{CH}_{4}$ detection could be facilitated in the weak hot lines to avoid strong absorption interfering with the signal generation. Also, many hydrocarbons have absorption lines in this wavelength region, and sometimes the infrared spectrum in combustion situations is very complicated. Detailed knowledge of the line position and intensity of both weak and strong lines in the $\mathrm{CH}_{4}$ spectrum can help to discriminate $\mathrm{CH}_{4}$ lines against lines from other hydrocarbons. 


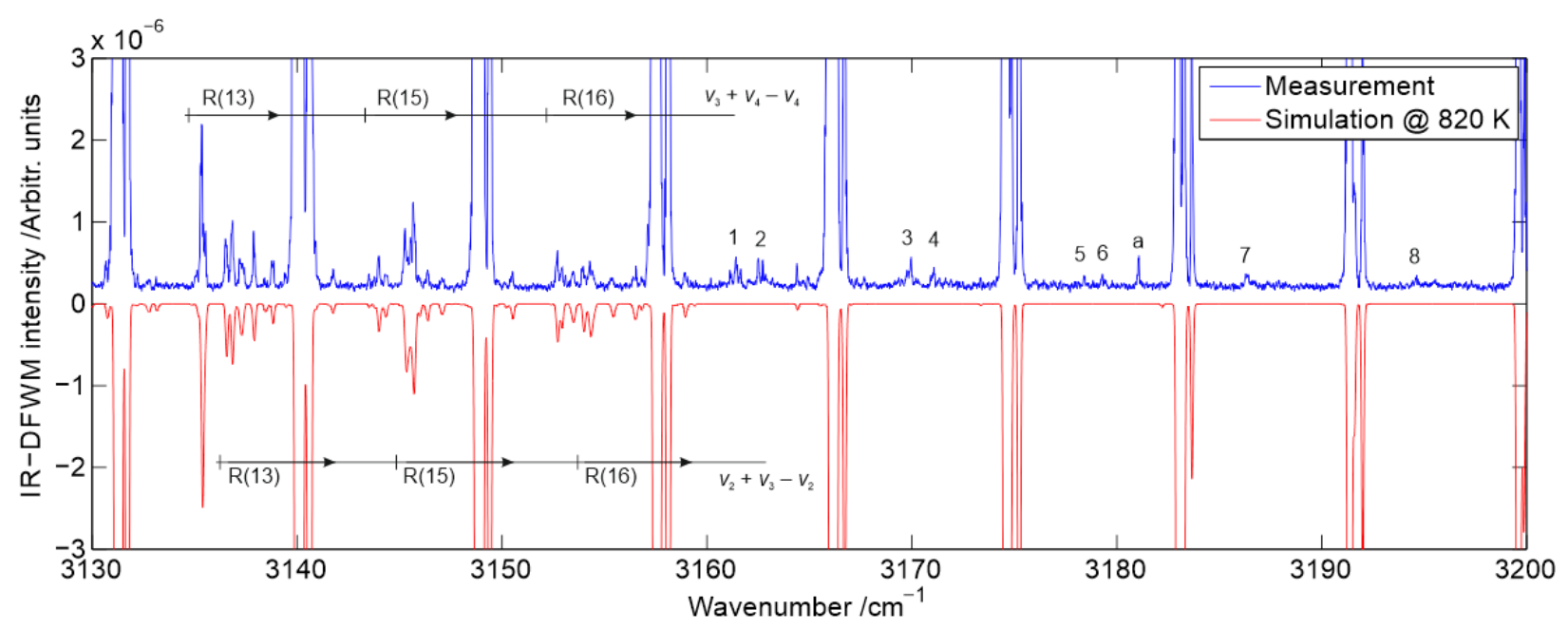

Figure 5. The infrared degenerate four-wave mixing (IR-DFWM) spectrum of $2100 \mathrm{ppm} \mathrm{CH}_{4}$ diluted in $\mathrm{N}_{2}$ at $820 \mathrm{~K}$. The $y$-axis of the graph has been adjusted in order to highlight the weaker appearing hot lines. Selected hot lines present in the simulation are identified in the figure. Above $3160 \mathrm{~cm}^{-1}$, there are hot lines in the spectrum (numbered 1-8) that are not present in the simulation. The line marked ' $a$ ' at $3181.06 \mathrm{~cm}^{-1}$ matches a $\mathrm{H}_{2} \mathrm{O}$ hot line, so it could arise from water vapor diffusing into the heating tube from the ambient air. The intensity of the simulated spectrum was normalized to the best fit to the measurements.

$\mathrm{C}_{2} \mathrm{H}_{4}$

The IR-DFWM excitation scan recorded at $820 \mathrm{~K}$ in a gas flow containing $1.3 \% \mathrm{C}_{2} \mathrm{H}_{4}$ is shown in Figure 6 (blue) compared with the simulated IR-DFWM signal (red). The figure contains line notations for several ${ }^{P} Q_{K}$ and ${ }^{R} Q_{K}$-lines of the $v_{9}$ band and the ${ }^{Q} Q$-line of the $v_{11}$ band. The measured and simulated IR-DFWM spectra at 269 and $550 \mathrm{~K}$ are shown in Supplementary information Figure S3, and text files containing the raw data for the measured spectra are also included in Supplementary information.

Comparing the measurement and the simulation, it is clear that while the overall shape of the measurement agrees with the simulation, clear discrepancies exist in the relative intensity of the ${ }^{P} Q_{K}$ and ${ }^{R} Q_{K}$-lines of the $v_{9}$ band compared to the ${ }^{Q} Q$-line of the $v_{11}$ band to the simulation. At room temperature, the intensity of most ${ }^{P} Q_{K}$ and ${ }^{R} Q_{K}$ lines of the $v_{9}$ band is higher in the measurement than the simulation predicts. At higher temperatures, the line strength of the measured ${ }^{Q} Q$ line of the $v_{11}$ band at $2988 \mathrm{~cm}^{-1}$ decreases rapidly, although the line strength of the simulation is still strong. One cause for this could be the spread of transition intensity to higher $J$-values. Most probably, the simple empirical formula used for simulations in this article is not good enough to correctly predict the IR-DFWM signal for the complicated $\mathrm{C}_{2} \mathrm{H}_{4}$ spectrum. The IR-DFWM signals for lines containing many closely spaced transitions, for example the ${ }^{P} Q_{6}$-line in Figure 6, have much higher intensity than the signals from single lines. ${ }^{[11]}$ This enables measurements with more sensitive detection limits even for relatively weak line strength for individual lines, and also the possibility of better discrimination against interfering lines due to the high contrast to the background of weak lines in the spectrum. 


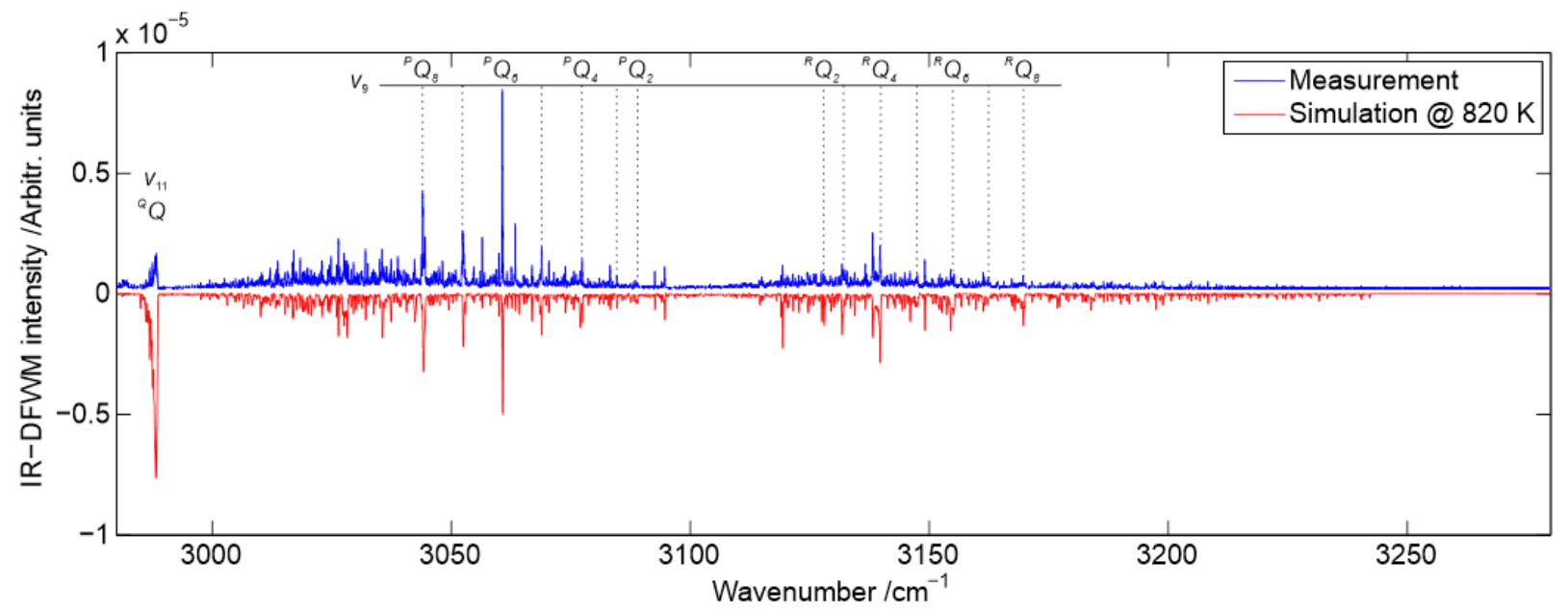

Figure 6. Infrared degenerate four-wave mixing (IR-DFWM) spectra of $1.3 \% \mathrm{C}_{2} \mathrm{H}_{4}$ diluted in $\mathrm{N}_{2}$ at $820 \mathrm{~K}$. A neutral density filter was used to dampen the signal intensity by a factor of 5 in order to avoid saturation of the detector. The intensity of the simulated spectrum was normalized to the best fit to the measurements.

At higher temperatures, the intensity of the lines in the wings of the spectrum increases. ${ }^{[17]}$ Figure 7 shows the IR-DFWM signal of $\mathrm{C}_{2} \mathrm{H}_{4}$ in the interval $3200-3280 \mathrm{~cm}^{-1}$. This spectrum was recorded with a higher $\mathrm{C}_{2} \mathrm{H}_{4}$ concentration to highlight the weaker lines in the wings of the spectrum. The HITRAN database for $\mathrm{C}_{2} \mathrm{H}_{4}$ in this spectral region contains no lines for higher wavenumbers than $3242.3 \mathrm{~cm}^{-1}$. The spectrum in Figure 7 shows a number of lines with significant line strength in the interval $3242.3-3280 \mathrm{~cm}^{-1}$, indicated with numbers $1-21$ in the figure.

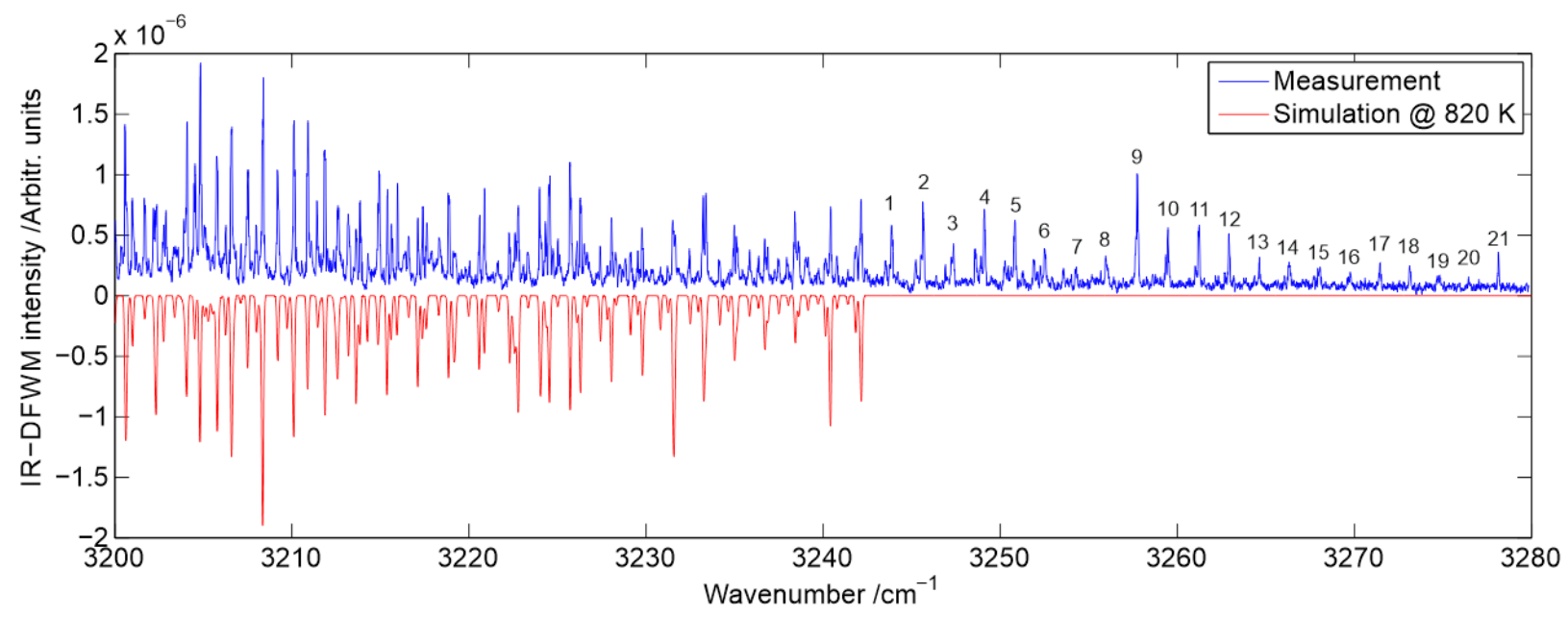

Figure 7. Infrared degenerate four-wave mixing (IR-DFWM) spectrum of $3.8 \% \mathrm{C}_{2} \mathrm{H}_{4}$ diluted in $\mathrm{N}_{2}$ at $820 \mathrm{~K}$ in the interval $3200-3280 \mathrm{~cm}^{-1}$. The intensity of the simulated spectrum was normalized to the best fit to the measurements.

$\mathrm{C}_{2} \mathrm{H}_{6}$

The IR-DFWM excitation scan recorded at $820 \mathrm{~K}$ in a gas flow containing $2020 \mathrm{ppm}_{2} \mathrm{H}_{6}$ is shown in Figure 8 (blue) compared with the simulated IR-DFWM signal (red). The strong ${ }^{R} Q_{K}$-branch 
lines from the $v_{7}$ band are identified by comparison with the HITRAN data. The measured and simulated IR-DFWM spectra at 269 and $550 \mathrm{~K}$ are shown in Supplementary information Figure S4, and text files containing the raw data for the measured spectra are also included in Supplementary information.

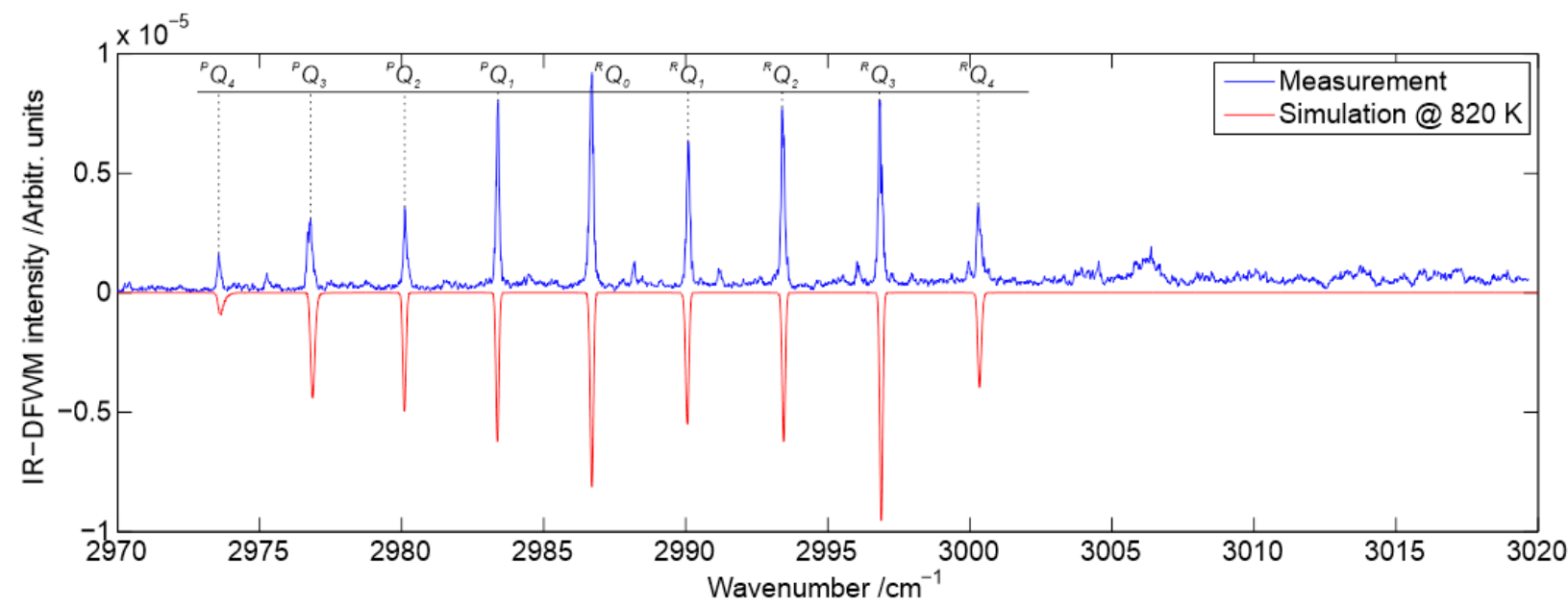

Figure 8. Infrared degenerate four-wave mixing (IR-DFWM) spectra of $2020 \mathrm{ppm} \mathrm{C}_{2} \mathrm{H}_{6}$ diluted in $\mathrm{N}_{2}$ at $820 \mathrm{~K}$. The intensity of the simulated spectrum was normalized to the best fit to the measurements.

As previously mentioned, the HITRAN database lacks spectroscopic information for the weaker $\mathrm{C}_{2} \mathrm{H}_{6}$ absorption lines in this region. The IR-DFWM measurement, on the other hand, shows several of these weaker lines in the spectrum. Shown in Figure 9 is the measured IR-DFWM spectrum at $296 \mathrm{~K}$ in the interval $3001-3040 \mathrm{~cm}^{-1}$ (blue) compared with the square of the absorption cross section (red) from Harrison et al. ${ }^{[16,23]}$ In this interval, the square of the absorption cross section seems to be a good approximation of the relative IR-DFWM signal. Figure 10 shows the IR-DFWM spectrum in the same interval at 296 (blue), 550 (red) and $820 \mathrm{~K}$ (green). The intensities of the scans in this figure have been normalized to the peak intensity of the $820 \mathrm{~K}$ measurement. While the same spectral structures are visible at all temperatures, the relative intensity of the lines at higher wavenumber increases with temperature. The number of lines in the spectrum also increases at higher temperatures, making it harder to distinguish between individual lines. 


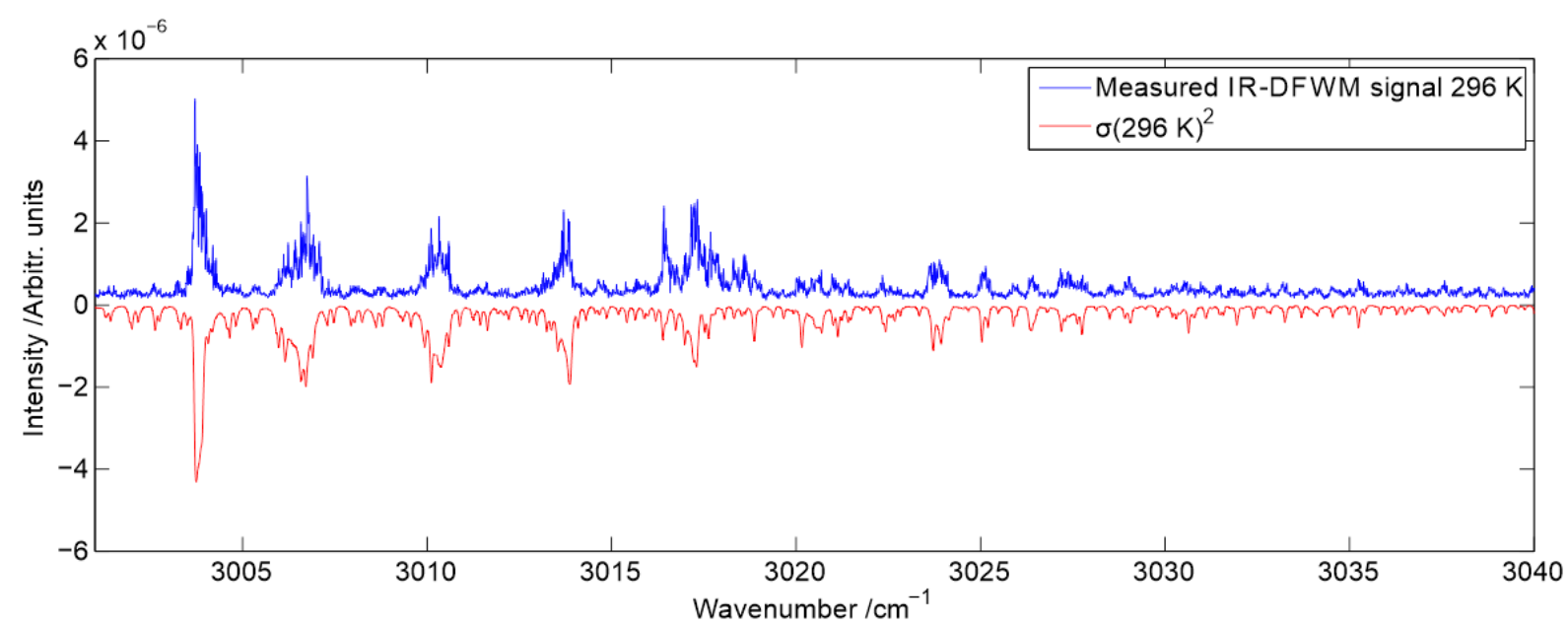

Figure 9. Comparison between the measured infrared degenerate four-wave mixing spectrum of $225 \mathrm{ppm} \mathrm{C}_{2} \mathrm{H}_{6}$ diluted in $\mathrm{N}_{2}$ at $296 \mathrm{~K}$ (blue) and the square of the absorption cross section of $\mathrm{C}_{2} \mathrm{H}_{6}$ at $296 \mathrm{~K}(\mathrm{red})$ in the interval $3001-3040 \mathrm{~cm}^{-1}$. The intensity of the absorption cross section squared has been adjusted to match the measurement.

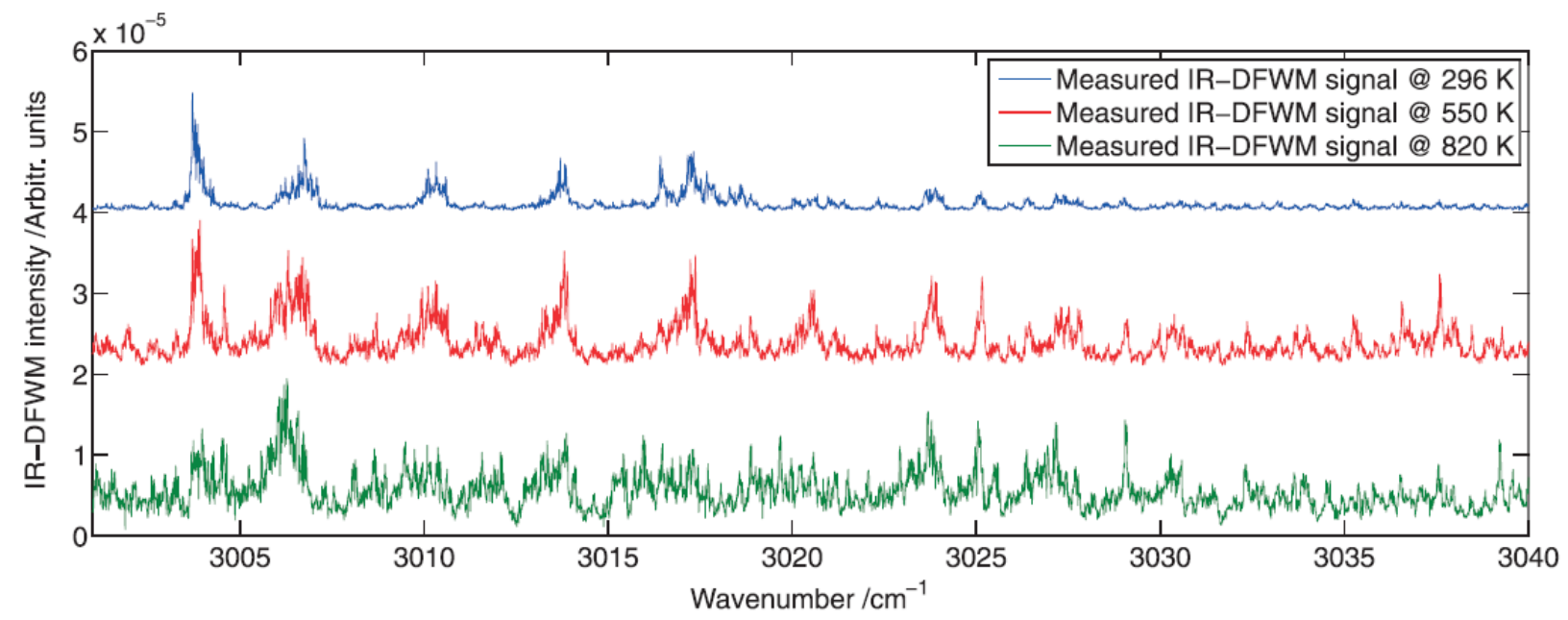

Figure 10. Infrared degenerate four-wave mixing (IR-DFWM) spectra for $\mathrm{C}_{2} \mathrm{H}_{6}$ diluted in $\mathrm{N}_{2}$ at 296 (blue), 550 (red) and $820 \mathrm{~K}$ (green). The curves have been offset in the plot to facilitate comparison of the spectral structures, and the intensities of the spectra have been normalized to the $820 \mathrm{~K}$ spectrum peak intensity. The concentration of $\mathrm{C}_{2} \mathrm{H}_{6}$ in the flows was $225 \mathrm{ppm}, 900 \mathrm{ppm}$ and $1.07 \%$ for the 296, 550 and $820 \mathrm{~K}$ measurements, respectively.

\section{Detection limits}

The concentration dependence of the IR-DFWM signal was measured for each species at 296, 550 and $820 \mathrm{~K}$. Figure 11 shows the line-integrated IR-DFWM signal of the $P(13)$ line of the $v_{2}+\left(v_{4}+v_{5}\right)^{0}$ band of $\mathrm{C}_{2} \mathrm{H}_{2}$ as a function of $\mathrm{C}_{2} \mathrm{H}_{2}$ concentration at $296 \mathrm{~K}$. Each point is an average of five scans, and the standard deviation of the five measurements is presented by the error bars. It can be seen that the IR-DFWM signal is proportional to the square of number density of the species as expected. Similar measurements were performed for $\mathrm{CH}_{4}, \mathrm{C}_{2} \mathrm{H}_{4}$ and $\mathrm{C}_{2} \mathrm{H}_{6}$ at 296, 550 and 820 
$\mathrm{K}$, and the detection limit was estimated for each measurement by extrapolating the curve down to a concentration where the estimated signal to noise ratio is 1 . Table 1 summarizes the detection limits of $\mathrm{C}_{2} \mathrm{H}_{2}, \mathrm{CH}_{4}, \mathrm{C}_{2} \mathrm{H}_{4}$ and $\mathrm{C}_{2} \mathrm{H}_{6}$ at 296, 550 and $820 \mathrm{~K}$. For each species, at each temperature, the line with highest intensity in the spectrum was chosen for the detection limit measurement. The spectral information for the lines used for estimation of the detection limit is shown in Table 2. For $\mathrm{C}_{2} \mathrm{H}_{2}$ at 550 and $820 \mathrm{~K}$, the strongest line was the combination of the $R(17)$ line of the $v_{3}$ band and the $R(23)$ line of the $v_{2}+\left(v_{4}+v_{5}\right)^{0}$ band, which occur at almost exactly the same wavelength.

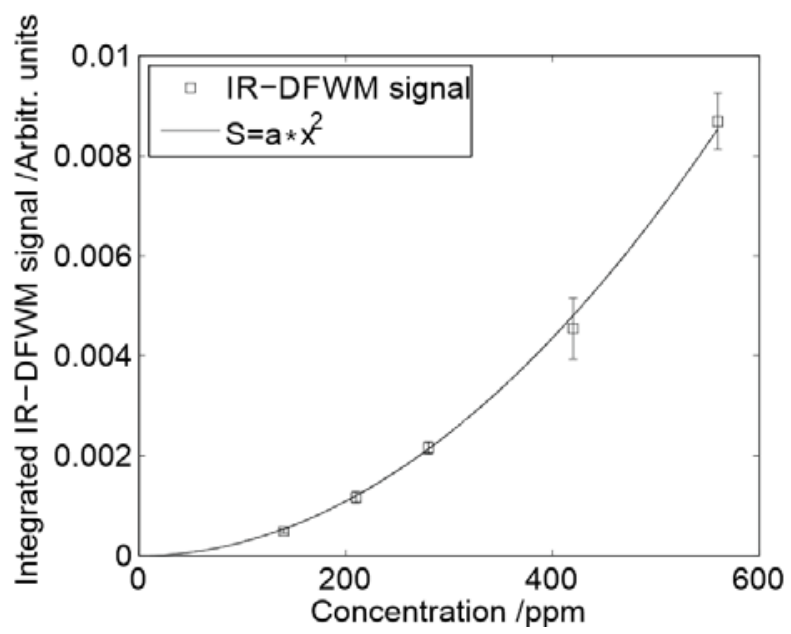

Figure 11. The concentration dependence of the line-integrated infrared degenerate four-wave mixing (IR-DFWM) signal intensity for $\mathrm{C}_{2} \mathrm{H}_{2}$ diluted in $\mathrm{N}_{2}$ at $296 \mathrm{~K}$.

Table 1. Estimated detection limits of $\mathrm{C}_{2} \mathrm{H}_{2}, \mathrm{CH}_{4}, \mathrm{C}_{2} \mathrm{H}_{4}$ and $\mathrm{C}_{2} \mathrm{H}_{6}$ at 296, 550 and $820 \mathrm{~K}$.

\begin{tabular}{|c|c|c|c|c|}
\hline \multirow[b]{2}{*}{ Temperature } & \multicolumn{4}{|c|}{ Detection limit / molecules $/ \mathrm{cm}^{3}$ (ppm) } \\
\hline & $\mathrm{C}_{2} \mathrm{H}_{2}$ & $\mathrm{CH}_{4}$ & $\mathrm{C}_{2} \mathrm{H}_{4}$ & $\mathrm{C}_{2} \mathrm{H}_{6}$ \\
\hline $296 \mathrm{~K}$ & $3.0 \cdot 10^{14}(12)$ & $1.2 \cdot 10^{14}(5)$ & $20 \cdot 10^{14}(79)$ & $2.0 \cdot 10^{14}(8)$ \\
\hline $550 \mathrm{~K}$ & $3.1 \cdot 10^{14}(23)$ & $1.7 \cdot 10^{14}(13)$ & $17 \cdot 10^{14}(131)$ & $3.7 \cdot 10^{14}(28)$ \\
\hline $820 \mathrm{~K}$ & $6.1 \cdot 10^{14}(68)$ & $3.5 \cdot 10^{14}(39)$ & $35 \cdot 10^{14}(392)$ & $12 \cdot 10^{14}(139)$ \\
\hline
\end{tabular}

\section{Water interference and combustion diagnostics applications}

IR-DFWM has good potential for sensitive, spatially resolved, non-intrusive measurements of hydrocarbon fuels and intermediate species in combustion situations. For combustion applications in the mid-infrared spectral region, the interference from water lines needs to be taken into consideration. Figure 12 shows a recorded IR-DFWM excitation scan of $\mathrm{H}_{2} \mathrm{O}$ diluted in $\mathrm{N}_{2}$. The $\mathrm{H}_{2} \mathrm{O}$ vapor was generated by sending the $\mathrm{N}_{2}$ gas flow through a water bubbler, which was placed in a water bath kept at $70{ }^{\circ} \mathrm{C}$ to provide a water vapor pressure of $31 \mathrm{kPa}$, giving a concentration 
of $\mathrm{H}_{2} \mathrm{O}$ in the $\mathrm{N}_{2}$ flow of approximately $30 \%$. The gas flow was then sent through the heating tube and heated to $820 \mathrm{~K}$.

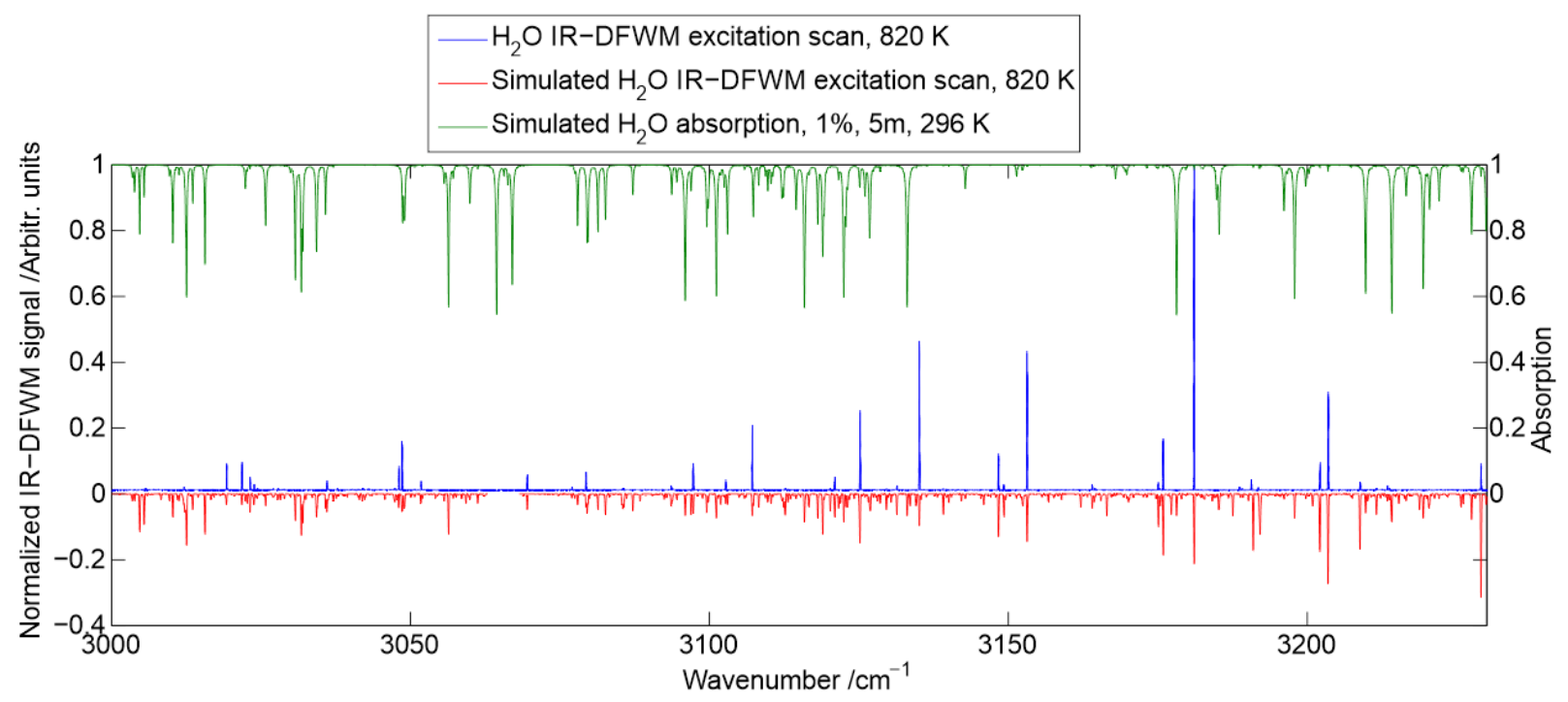

Figure 12. Infrared degenerate four-wave mixing (IR-DFWM) excitation scan of H2O diluted in $\mathrm{N} 2$ at $820 \mathrm{~K}$ (blue), compared with a simulated IR-DFWM spectrum of $\mathrm{H} 2 \mathrm{O}$ at $820 \mathrm{~K}$ using data from the HITEMP database (red) and a simulation of the absorption spectrum of $\mathrm{H} 2 \mathrm{O}$ at $296 \mathrm{~K}$ for a concentration of $1 \%$ and a path length of $5 \mathrm{~m}$ (green). The IR-DFWM excitation scan has been normalized to the peak intensity and the intensity of the simulated IR-DFWM spectrum has been adjusted to best fit the measurement.

Table 2: Line used for detection limit measurements for the different species and temperatures

\begin{tabular}{|c|c|c|c|c|c|c|}
\hline \multirow{3}{*}{$\mathrm{C}_{2} \mathrm{H}_{2}$} & \multirow{2}{*}{\multicolumn{2}{|c|}{$\begin{array}{l}296 \mathrm{~K} \\
\text { Rotation line }\end{array}$}} & \multicolumn{2}{|r|}{$\underline{550 \mathrm{~K}}$} & \multicolumn{2}{|r|}{$\underline{820 ~ K}$} \\
\hline & & & $\begin{array}{l}\text { Vibration } \\
\text { mode }\end{array}$ & Rotation line & $\begin{array}{l}\text { Vibration } \\
\text { mode }\end{array}$ & Rotation line \\
\hline & $v_{2}+\left(v_{4}+v_{5}\right)^{0}$ & $P(13) 3250.66 \mathrm{~cm}^{-1}$ & $\begin{array}{l}v_{3} \\
v_{2}+\left(v_{4}+v_{5}\right)^{0}\end{array}$ & $\begin{array}{l}R(17) 3335.55 \mathrm{~cm}^{-1} \\
R(23) 3335.56 \mathrm{~cm}^{-1}\end{array}$ & $\begin{array}{l}v_{3} \\
v_{2}+\left(v_{4}+v_{5}\right)^{0}\end{array}$ & $\begin{array}{l}R(17) 3335.55 \mathrm{~cm}^{-1} \\
R(23) 3335.56 \mathrm{~cm}^{-1}\end{array}$ \\
\hline $\mathrm{CH}_{4}$ & $v_{3}$ & $R(3) 3057.72 \mathrm{~cm}^{-1}$ & $v_{3}$ & $R(9) 3113.33 \mathrm{~cm}^{-1}$ & $v_{3}$ & $R(9) 3113.33 \mathrm{~cm}^{-1}$ \\
\hline $\mathrm{C}_{2} \mathrm{H}_{6}$ & $v_{7}$ & ${ }^{R} Q_{0} 2986.71 \mathrm{~cm}^{-1}$ & $v_{7}$ & ${ }^{R} Q_{0} 2986.71 \mathrm{~cm}^{-1}$ & $v_{7}$ & ${ }^{R} Q_{0} 2986.71 \mathrm{~cm}^{-1}$ \\
\hline $\mathrm{C}_{2} \mathrm{H}_{4}$ & $V_{9}$ & ${ }^{P} Q_{6} 3060.78 \mathrm{~cm}^{-1}$ & $V_{9}$ & ${ }^{P} Q_{6} 3060.78 \mathrm{~cm}^{-1}$ & $v_{9}$ & ${ }^{P} Q_{6} 3060.78 \mathrm{~cm}^{-1}$ \\
\hline
\end{tabular}

The IR-DFWM excitation scan of $\mathrm{H}_{2} \mathrm{O}$ at $820 \mathrm{~K}$ is compared to a simulated IR-DFWM scan using data extracted from the HITEMP database. Comparing the simulated and recorded spectra, it is clear that a lot of lines from the simulation are missing in the measurement. This has been observed previously with a similar setup for measurement of hot $\mathrm{H}_{2} \mathrm{O}$ spectral lines. ${ }^{[11]}$ It was found that absorption of the laser energy by cold water in the ambient laboratory air was responsible for this 
lack of signals. In the upper part of Figure 12 is a simulated absorption spectrum of $\mathrm{H}_{2} \mathrm{O}$ in the air for a concentration of $1 \%$ and a path length of $5 \mathrm{~m}$ using HITRAN database. As can be seen, a large part of the laser energy is absorbed at certain lines, which causes the signal to disappear at these wavelengths. Thus, only the hot $\mathrm{H}_{2} \mathrm{O}$ lines, which has negligible absorption at $296 \mathrm{~K}$, show up in the $820 \mathrm{~K}$ spectrum. These line-missing phenomena might also exist for hydrocarbon spectra. The line positions of these hot lines seem well matched with the HITEMP database, although discrepancies exist in the relative line intensities. As mentioned before, the $\mathrm{H}_{2} \mathrm{O}$ spectrum is complicated and the empirical model used for simulations may not be accurate for complex spectra.

Despite the obvious differences between the measured and simulated $\mathrm{H}_{2} \mathrm{O}$ spectrum in Figure 12, the HITEMP simulation seems reasonably reliable for the position and approximate intensity of hot $\mathrm{H}_{2} \mathrm{O}$ lines in this spectral range. Figure 13 shows the measured $\mathrm{CH}_{4}, \mathrm{C}_{2} \mathrm{H}_{2}, \mathrm{C}_{2} \mathrm{H}_{4}$ and $\mathrm{C}_{2} \mathrm{H}_{6}$ spectra at $820 \mathrm{~K}$ compared with a simulation of the $\mathrm{H}_{2} \mathrm{O}$ spectrum from the HITEMP database at $820 \mathrm{~K}$. The line intensities of the simulation have been adjusted to the scale of the measurement in each figure. According to these simulations, while water interference is always present in this spectral region, it is fairly easy to find a strong spectral line for these species that is isolated from water interference. The source data file for the spectra shown in Figure 12 are included in the supplements.
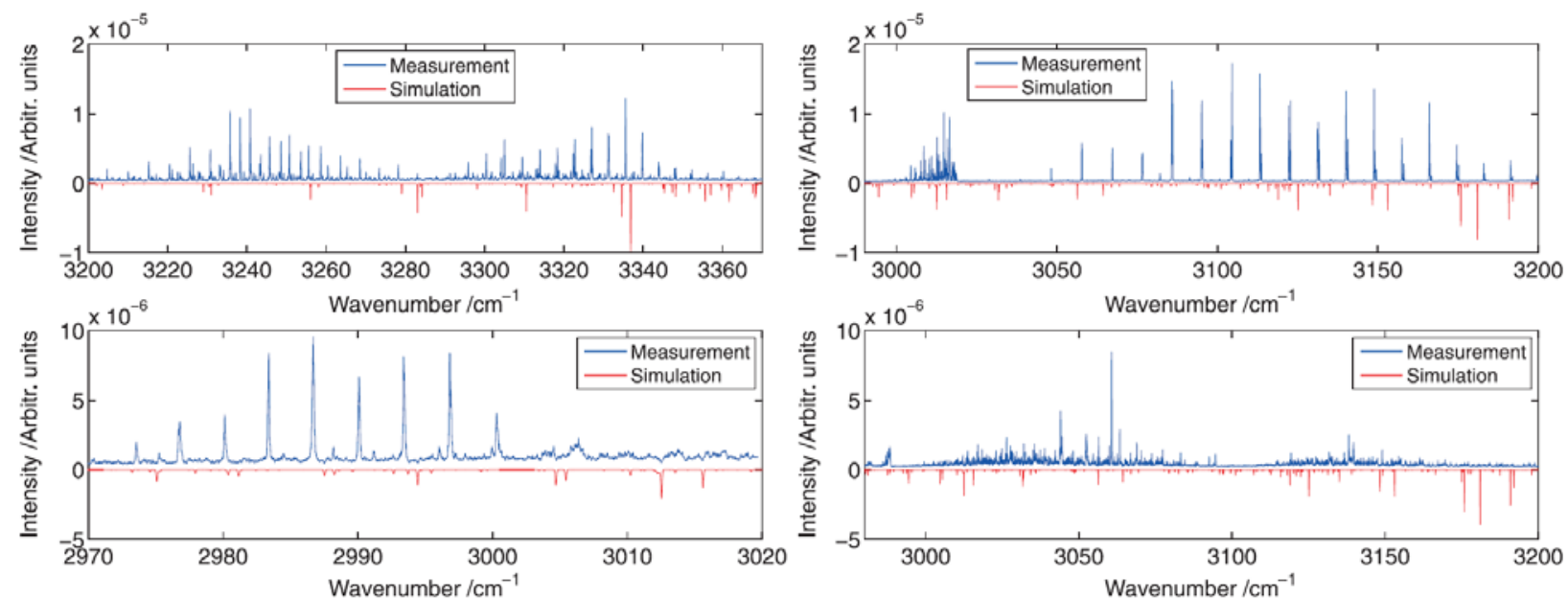

Figure 13. A comparison between the measured Infrared degenerate four-wave mixing (IRDFWM) spectra (blue) for (a) $\mathrm{C}_{2} \mathrm{H}_{2}$, (b) $\mathrm{CH}_{4}$, (c) $\mathrm{C}_{2} \mathrm{H}_{6}$ and (d) $\mathrm{C}_{2} \mathrm{H}_{4}$ (red) and the simulated $\mathrm{H}_{2} \mathrm{O}$ IR-DFWM spectrum at $820 \mathrm{~K}$. The intensities of the simulations have been adjusted to match the signal strength in the measurement.

In addition to water interference, interference from other hydrocarbon species has to be considered. Most combustion environments contain a large number of unburned fuel and intermediate hydrocarbons, most of which have absorption lines in the wavelength region studied here. Due to this, mid-infrared spectra recorded in combustion environments are generally complicated. A reliable high-temperature database for hydrocarbon molecules is crucial to be able to identify spectral lines belonging to certain species. As can be seen in the recorded spectra, the small hydrocarbons studied here have sharp spectral features, and the high resolution of the IR-DFWM 
technique makes it an excellent tool for separating line features and identifying molecular species in combustion environments.

\section{Conclusions}

It has been shown that IR-DFWM has a strong potential for in situ detection of hydrocarbon molecules and investigations of spectral lines at elevated temperatures. IR-DFWM has the advantage over FTIR in that the temperature of the investigated gas sample only needs to be homogeneous in a small volume, thus eliminating the problem of creating a gas sample with homogeneous temperature along the line of the measurement. Thus, IR-DFWM can be a useful complement to absorption based techniques for spectroscopic measurements at high temperatures. The high sensitivity provides the potential of measurements of hot lines that are too weak to be detected by other techniques.

For applications in combustion diagnostics, the detection limit of the species as a function of temperature shows a good sensitivity even at elevated temperatures. Detailed knowledge of the spectral line positions and intensities at elevated temperatures is a valuable tool for spectral line identification in flame spectra. The experimentally measured spectral data of the selected small hydrocarbons, prepared in Supplementary information, will serve this purpose. Measurements and simulations of the $\mathrm{H}_{2} \mathrm{O}$ spectrum at elevated temperatures show that the interference from water lines is not a big problem for these species. Besides, the nonlinear nature of IR-DFWM provides much higher contrast for strong lines of small molecules over backgrounds of high density weak lines, which commonly exist in hot gas flows of thermochemical reactions. The IR-DFWM signal will also be much enhanced for line groups of several closely spaced transitions, i.e. certain $Q$ branch lines, which is evident in the presented $\mathrm{C}_{2} \mathrm{H}_{4}$ and $\mathrm{C}_{2} \mathrm{H}_{6}$ spectra. This provides the possibility for more sensitive detection of species with spectra containing such features. The technique could be expanded for single shot species detection of hydrocarbons in flames using broadband lasers to excite many absorption lines simultaneously. However, to the best of our knowledge, there is limited availability of suitable high power, broadband laser sources and sensitive, high resolution spectrometers in the mid-infrared spectral region, which limits the applications of broadband IRDFWM.

\section{Acknowledgement}

This work was financed by the Swedish Energy Agency, Knut \& Alice Wallenberg foundation, VR (Swedish Research Council) and the European Research Council.

\section{References}

[1] R. L. Abrams, R. C. Lind, Opt. Lett. 1978; 2, 94.

[2] R. L. Abrams, R. C. Lind, Opt. Lett. 1978; 3, 205.

[3] R. L. Farrow, D. J. Rakestraw, T. Dreier, J. Opt. Soc. Am. B 1992; 9, 1770.

[4] T. Dreier, D. J. Rakestraw, Appl. Phys. B: Photophys. Laser Chem. 1990; 50, 479.

[5] P. Ewart, S. V. O'Leary, Opt. Lett. 1986; 11, 279.

[6] T. Dreier, D. J. Rakestraw, Opt. Lett. 1990; 15, 72.

[7] G. J. Germann, R. L. Farrow, D. J. Rakestraw, J. Opt. Soc. Am. B 1995; 12, 25.

[8] R. L. Vander Wal, B. E. Holmes, J. B. Jeffries, P. M. Danehy, R. L. Farrow, D. J. Rakestraw, Chem. Phys. Lett. 1992; 191, 251. 
[9] Y. Tang, S. A. Reid, Chem. Phys. Lett. 1996; 248, 476.

[10] Z. W. Sun, Z. S. Li, B. Li, M. Aldén, P. Ewart, Appl. Phys. B: Lasers Opt. 2010; 98, 593.

[11] A. L. Sahlberg, J. Zhou, M. Aldén, Z. S. Li, J. Raman Spectrosc. 2015; 46, 695.

[12] J. S. Dam, P. Tidemand-Lichtenberg, C. Pedersen, Nat. Photonics 2012; 6, 788.

[13] L. Høgstedt, J. S. Dam, A.-L. Sahlberg, Z. Li, M. Aldén, C. Pedersen, P. Tidemand-Lichtenberg, Opt. Lett. 2014; 39, 5321.

[14] P. S. Hsu, H. U. Stauffer, N. Jiang, J. R. Gord, S. Roy, J. Chem. Phys. 2013; 139, 154201.

[15] N. Chai, S. V. Naik, W. D. Kulatilaka, N. M. Laurendeau, R. P. Lucht, S. Roy, J. R. Gord, Appl. Phys. B: Lasers Opt. 2007; 87, 731.

[16] L. S. Rothman, I. E. Gordon, Y. Babikov, A. Barbe, D. Chris Benner, P. F. Bernath, M. Birk, L. Bizzocchi, V. Boudon, L. R. Brown, A. Campargue, K. Chance, E. A. Cohen, L. H. Coudert, V. M. Devi, B. J. Drouin, A. Fayt, J.-M. Flaud, R. R. Gamache, J. J. Harrison, J. M. Hartmann, C. Hill, J. T. Hodges, D. Jacquemart, A. Jolly, J. Lamouroux, R. J. Le Roy, G. Li, D. A. Long, O. M. Lyulin, C. J. Mackie, S. T. Massie, S. Mikhailenko, H. S. P. Müller, O. V. Naumenko, A. V. Nikitin, J. Orphal, V. Perevalov, A. Perrin, E. R. Polovtseva, C. Richard, M. A. H. Smith, E. Starikova, K. Sung, S. Tashkun, J. Tennyson, G. C. Toon, V. G. Tyuterev, G. Wagner, J. Quant. Spectrosc. Radiat. Transfer. 2013; 130, 4.

[17] M. Alrefae, E.-t. Es-sebbar, A. Farooq, J. Mol. Spectrosc. 2014; 303, 8.

[18] L. S. Rothman, I. E. Gordon, R. J. Barber, H. Dothe, R. R. Gamache, A. Goldman, V. I. Perevalov, S. A. Tashkun, J. Tennyson, J. Quant. Spectrosc. Radiat. Transfer 2010; 111, 2139.

[19] Z. S. Li, C. H. Hu, J. Zetterberg, M. Linvin, M. Alden, J. Chem. Phys. 2007; 127, 084310.

[20] M. P. Ruiz, A. Callejas, A. Millera, M. U. Alzueta, R. Bilbao, J. Anal. Appl. Pyrolysis 2007; 79, 244.

[21] C. Guéret, M. Daroux, F. Billaud, Chem. Eng. Sci. 1997; 52, 815.

[22] A. B. Trenwith, J. Chem. Soc., Faraday Trans. 2 1986; 82, 457.

[23] J. J. Harrison, N. D. C. Allen, P. F. Bernath, J. Quant. Spectrosc. Radiat. Transfer 2010; 111, 357.

[24] J. Kiefer, P. Ewart, Prog. Energy Combust. Sci. 2011; 37, 525.

[25] R. P. Lucht, R. L. Farrow, D. J. Rakestraw, J. Opt. Soc. Am. B 1993; 10, 1508.

[26] T. A. Reichardt, R. P. Lucht, J. Chem. Phys. 1998; 109, 5830.

[27] T. A. Reichardt, R. P. Lucht, J. Opt. Soc. Am. B 1997; 14, 2449.

[28] T. A. Reichardt, R. P. Lucht, J. Opt. Soc. Am. B 1996; 13, 1107.

[29] R. T. Bratfalean, G. M. Lloyd, P. Ewart, J. Opt. Soc. Am. B 1999; 16, 952.

[30] K. Bultitude, R. Bratfalean, P. Ewart, J. Raman Spectrosc. 2003; 34, 1030.

[31] K. Richard, P. Ewart, Appl. Phys. B: Lasers Opt. 2009; 94, 715. 


\section{Supplementary information}

\section{$\mathrm{C}_{2} \mathrm{H}_{2}$}

The IR-DFWM spectra of $\mathrm{C}_{2} \mathrm{H}_{2}$ recorded at temperature of 296,550 and $820 \mathrm{~K}$ is shown in Figure S1 (blue curves) compared with the relative simulated IR-DFWM signal (red curves) with line parameters extracted from HITRAN database. The spectral data for the measured IR-DFWM spectra is available in attached text files.
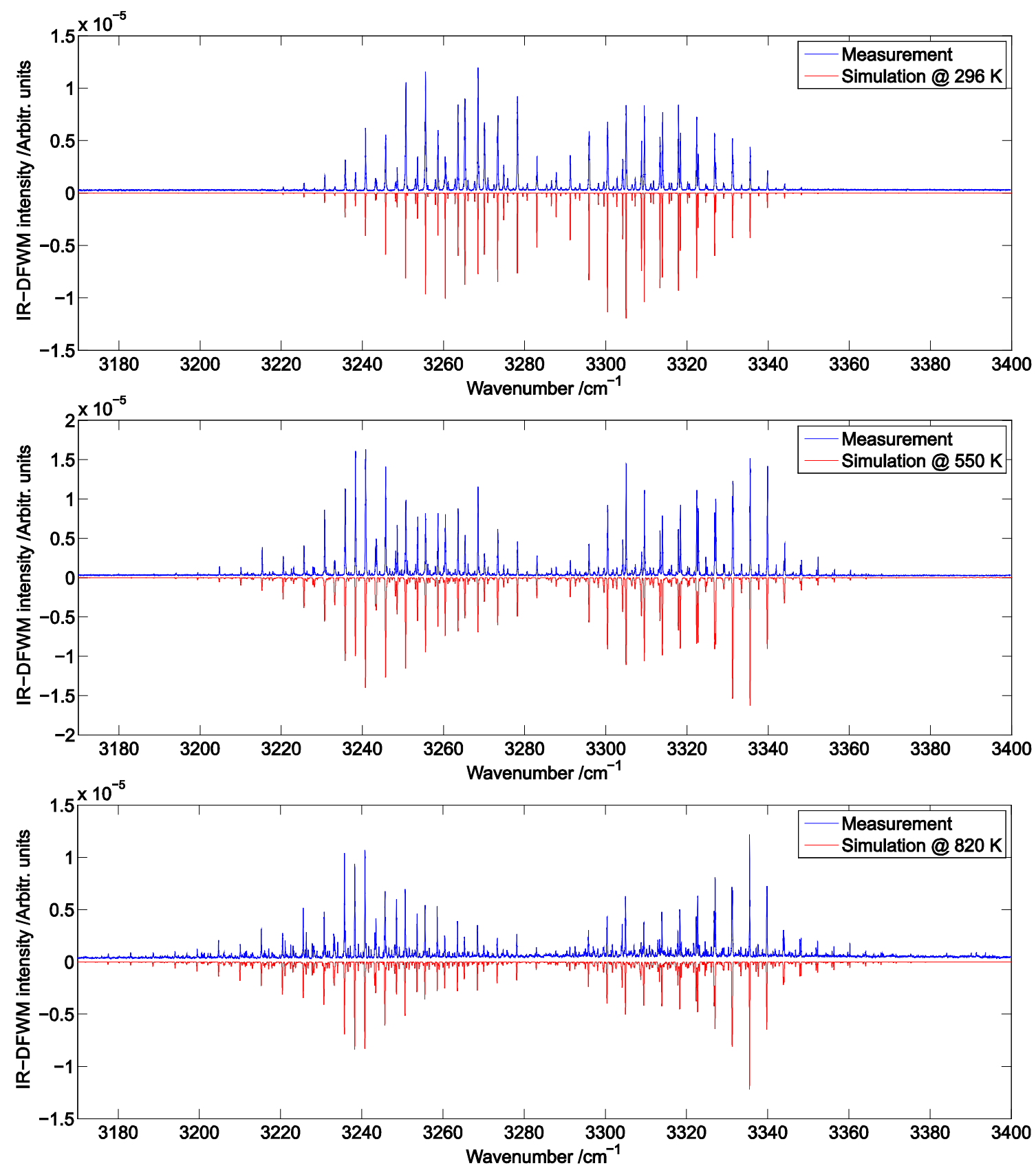

Figure S1: IR-DFWM spectra of $\mathrm{C}_{2} \mathrm{H}_{2}$ diluted in $\mathrm{N}_{2}$ at $296 \mathrm{~K}, 550 \mathrm{~K}$ and $820 \mathrm{~K}$. The concentrations of $\mathrm{C}_{2} \mathrm{H}_{2}$ in the gas flows were 560, 560 and 1110 ppm, respectively. A neutral density filter was used to dampen the signal intensity at $296 \mathrm{~K}$ by a factor of 5, and no filters were applied for $550 \mathrm{~K}$ and $820 \mathrm{~K}$ measurements. 


\section{$\mathrm{CH}_{4}$}

The IR-DFWM spectra of $\mathrm{CH}_{4}$ recorded at temperature of 296, 550 and $820 \mathrm{~K}$ is shown in Figure S2 (blue curves) compared with the simulated IR-DFWM signal (red curves) with line parameters extracted from HITRAN database. The data for the measured IR-DFWM spectra are included in attached text files.
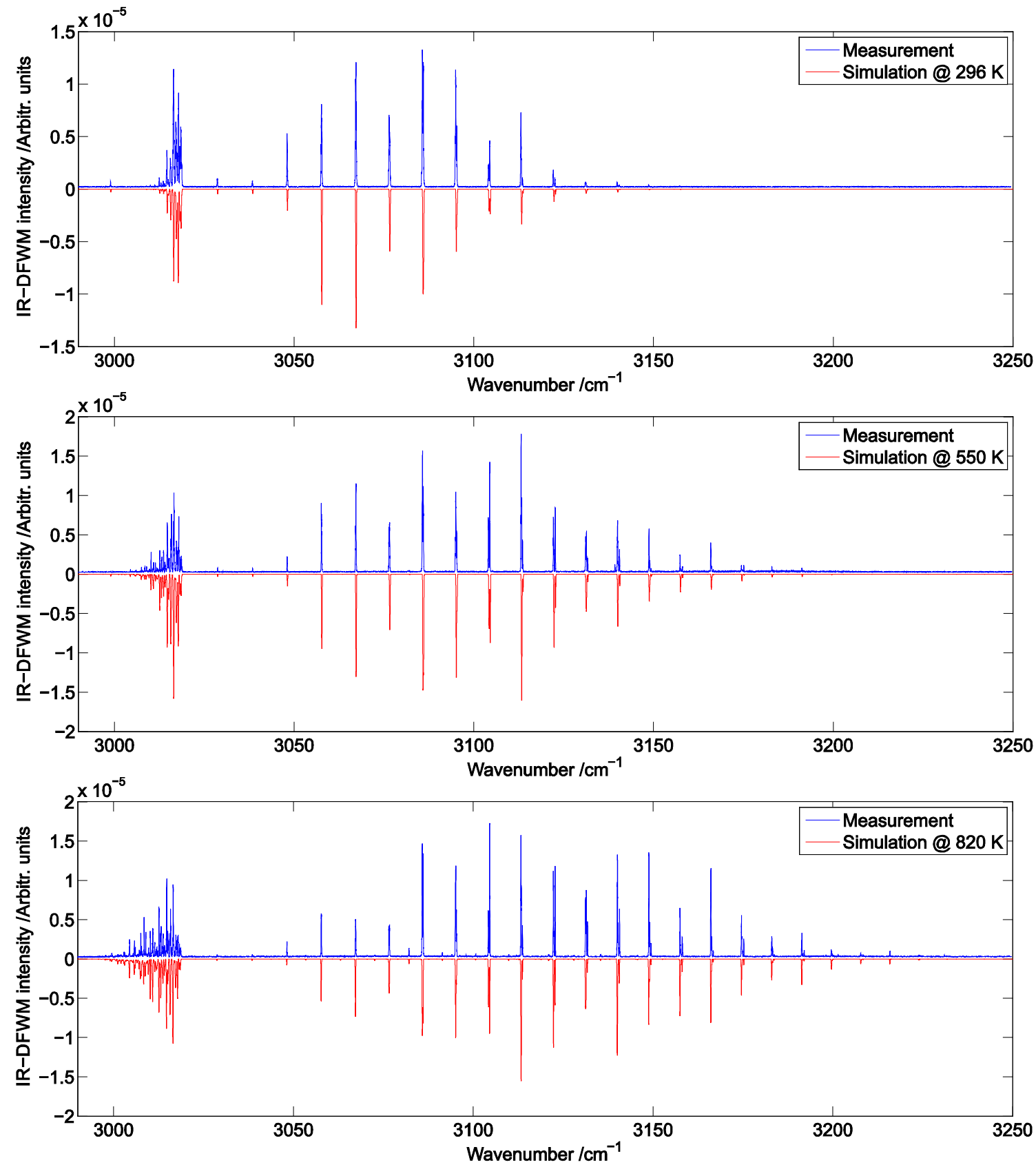

Figure S2: IR-DFWM spectra of $\mathrm{CH}_{4}$ diluted in $\mathrm{N}_{2}$ at 296, 550 and $820 \mathrm{~K}$. The concentrations of $\mathrm{CH}_{4}$ in the gas flows were 350, 350 and 700 ppm, respectively. A neutral density filter was used to dampen the signal intensity at $296 \mathrm{~K}$ by a factor of 10 , and no filters were applied at $550 \mathrm{~K}$ and $820 \mathrm{~K}$. 


\section{$\mathrm{C}_{2} \mathrm{H}_{4}$}

The IR-DFWM spectra of $\mathrm{C}_{2} \mathrm{H}_{4}$ at 296, 550 and $820 \mathrm{~K}$ are shown in Figure S3 (blue curves) compared with the simulated IR-DFWM signal (red curves) with line parameters extracted from HITRAN database. The data for the measured IR-DFWM spectra are included in attached text files.
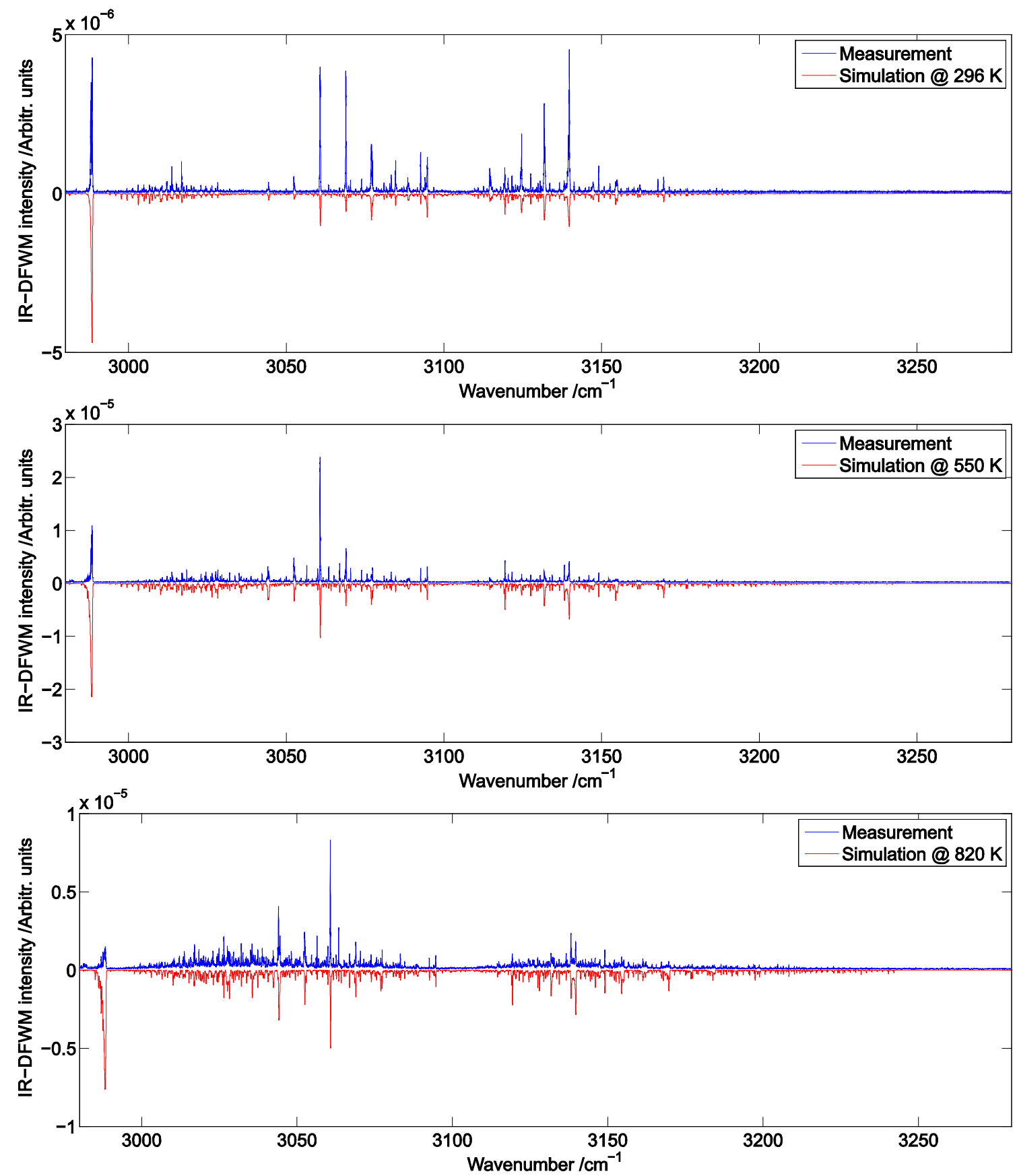

Figure S3: IR-DFWM spectra of $\mathrm{C}_{2} \mathrm{H}_{4}$ diluted in $\mathrm{N}_{2}$ at 296, 550 and $820 \mathrm{~K}$. The concentrations of $\mathrm{C}_{2} \mathrm{H}_{4}$ in the gas flows were $0.25 \%, 1.3 \%$ and $1.3 \%$, respectively. A neutral density filter was used to dampen the signal intensity at all measurements by a factor of 5 . 


\section{$\mathrm{C}_{2} \mathrm{H}_{6}$}

The IR-DFWM spectra of $\mathrm{C}_{2} \mathrm{H}_{6}$ at 296, 550 and $820 \mathrm{~K}$ is shown in Figure $\mathrm{S} 4$ (blue curves) compared with the simulated IR-DFWM signal (red curves) with line parameters extracted from HITRAN database. The data for the measured IR-DFWM spectra are included in attached text files.
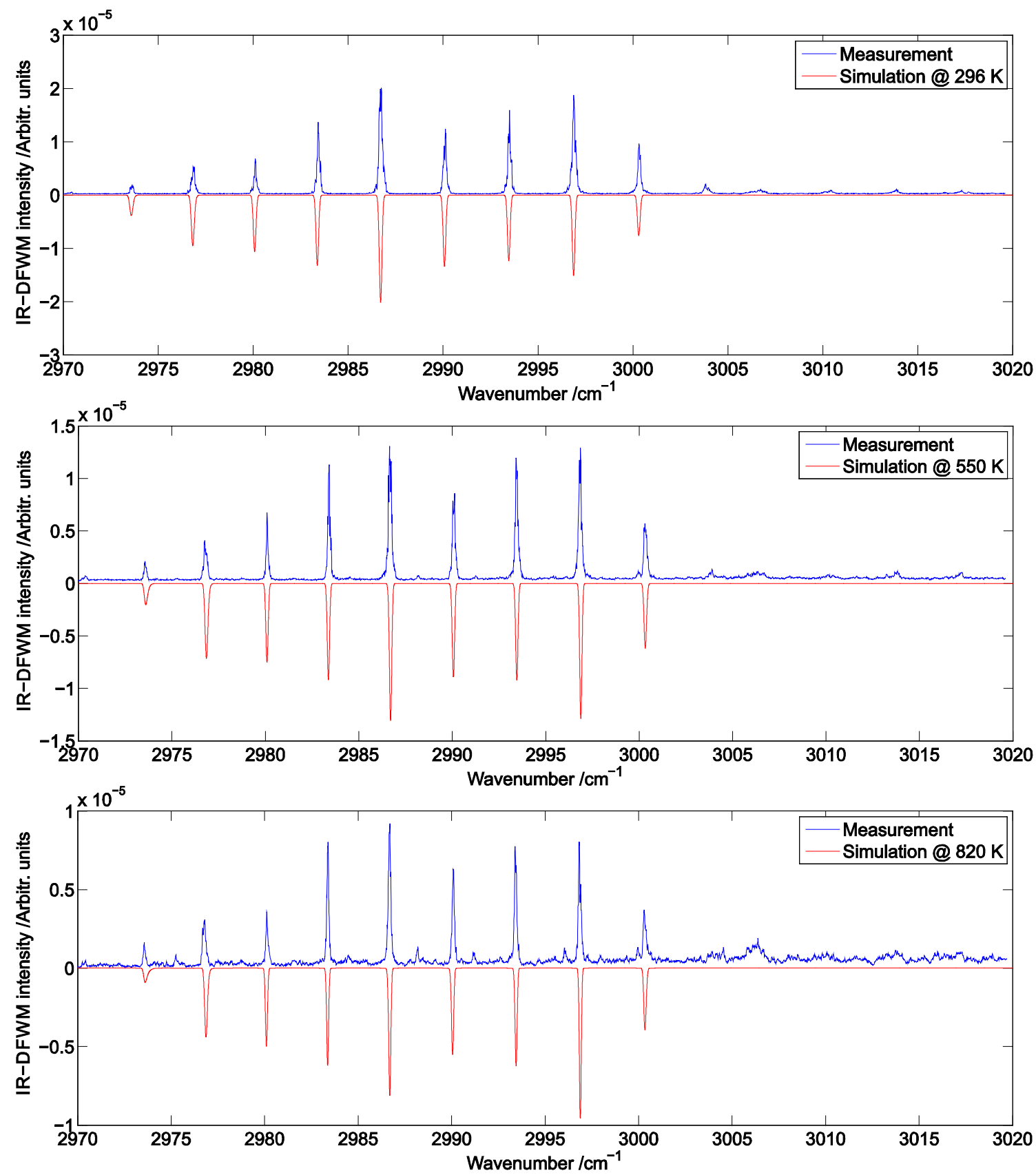

Figure S4: IR-DFWM spectra of $\mathrm{C}_{2} \mathrm{H}_{6}$ diluted in $\mathrm{N}_{2}$ at 296, 550 and $820 \mathrm{~K}$. The concentrations of $\mathrm{C}_{2} \mathrm{H}_{6}$ in the gas flows were 230, 450 and 2020 ppm at 296, 550 and $820 \mathrm{~K}$, respectively. A neutral density filter was used to dampen the signal intensity at $296 \mathrm{~K}$ by a factor of 5 , and no filters were applied at $550 \mathrm{~K}$ and $820 \mathrm{~K}$ 